\title{
Beyond the Brain: The Systemic Pathophysiological Response to Acute Ischemic Stroke
}

\author{
Maria H.H. Balch,,${ }^{\mathrm{a}, \mathrm{b}}$ Shahid M. Nimjee, ${ }^{\mathrm{a}}$ Cameron Rink, ${ }^{\mathrm{a}}$ Yousef Hannawi ${ }^{\mathrm{c}}$ \\ ${ }^{a}$ Department of Neurological Surgery, The Ohio State University Wexner Medical Center, Columbus, OH, USA \\ bDepartment of Biomedical Education and Anatomy, The Ohio State University College of Medicine, Columbus, OH, USA \\ 'Department of Neurology, The Ohio State University Wexner Medical Center, Columbus, OH, USA
}

Stroke research has traditionally focused on the cerebral processes following ischemic brain injury, where oxygen and glucose deprivation incite prolonged activation of excitatory neurotransmitter receptors, intracellular calcium accumulation, inflammation, reactive oxygen species proliferation, and ultimately neuronal death. A recent growing body of evidence, however, points to far-reaching pathophysiological consequences of acute ischemic stroke. Shortly after stroke onset, peripheral immunodepression in conjunction with hyperstimulation of autonomic and neuroendocrine pathways and motor pathway impairment result in dysfunction of the respiratory, urinary, cardiovascular, gastrointestinal, musculoskeletal, and endocrine systems. These end organ abnormalities play a major role in the morbidity and mortality of acute ischemic stroke. Using a pathophysiology-based approach, this current review discusses the pathophysiological mechanisms following ischemic brain insult that result in end organ dysfunction. By characterizing stroke as a systemic disease, future research must consider bidirectional interactions between the brain and peripheral organs to inform treatment paradigms and develop effective, comprehensive therapeutics for acute ischemic stroke.

Keywords Stroke; Disease progression; Pathologic processes; Physiopathology; Translational medical research
Correspondence: Yousef Hannawi Department of Neurology, The Ohio State University Wexner Medical Center, Graves Hall, Suite 3172C, 333 West 10th Ave, Columbus, $\mathrm{OH} 43210$, USA

Tel: +1-614-685-7234

Fax: +1-614-366-7004

E-mail:yousefhannawi@yahoo.com

Received: November 2, 2019

Revised: January 28, 2020

Accepted: March 17, 2020

\section{Introduction}

Acute ischemic stroke (AIS) is a major cause of mortality and long-term disability world-wide that lacks curative therapies. ${ }^{1,2}$ Recent key advancements in pharmacological thrombolysis and mechanical endovascular thrombectomy remain limited by a narrow therapeutic window and restrictive eligibility. ${ }^{3.4}$ Additionally, the spectrum of rehabilitation paradigms implores evidence base, ${ }_{1}^{5}$ while efforts targeting neuroprotection largely fail to translate to human therapies. ${ }^{6}$ AIS research has historically focused on these central nervous system (CNS) interventions to reduce infarct volume and address neuronal viability. More re- cently, however, detrimental effects of AIS on the heart ${ }^{7}$ and immune system ${ }^{8}$ have gained popularity. Indeed, medical complications following AIS such as pneumonia are strong predictors of mortality and functional outcome. ${ }^{9,10}$ To that end, we queried the National Center for Biotechnology Information and National Library of Medicine database through PubMed using a combination of keywords including "ischemic stroke" and the system of interest to identify relevant literature addressing systemic effects of AIS. We found a small but growing body of evidence pointing to far-reaching pathophysiological consequences in peripheral tissues including immune, respiratory, urinary, cardiovascular, gastrointestinal, musculoskeletal, and endocrine 
systems (Supplementary Figure 1). Following AIS, the majority of these organ systems suffer disturbances ranging in severity from subclinical laboratory abnormalities to life-threatening arrhythmias or infections (Figure 1). In this current review, we discuss the mechanisms by which AIS induces these systemic pathophysiological responses and summarize their subsequent clinical manifestations.

\section{The crosstalk between the stroke- affected brain and end organ systems}

It is now widely accepted that AIS has dramatic consequences on the fine balance between the brain and the rest of the human body (Table 1, Supplementary Table 1). ${ }^{9,11}$ Following AIS, many systems demonstrate time-dependent progression of acute stroke-induced alterations preceding chronic deficits

Autonomic nervous system and HPA axis

- Hyperactivation

- $\uparrow$ Catecholamines, glucocorticoids

- Enteric nervous system impairment

- Facilitation of organ system dysfunction

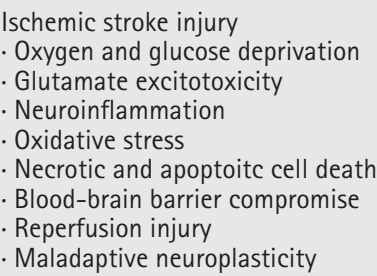

- Urinary tract infection

- Urinary incontinence

- Residual post-void volume

- Renal dysfunction

- Acute kidney injury

- Chronic kidney disease
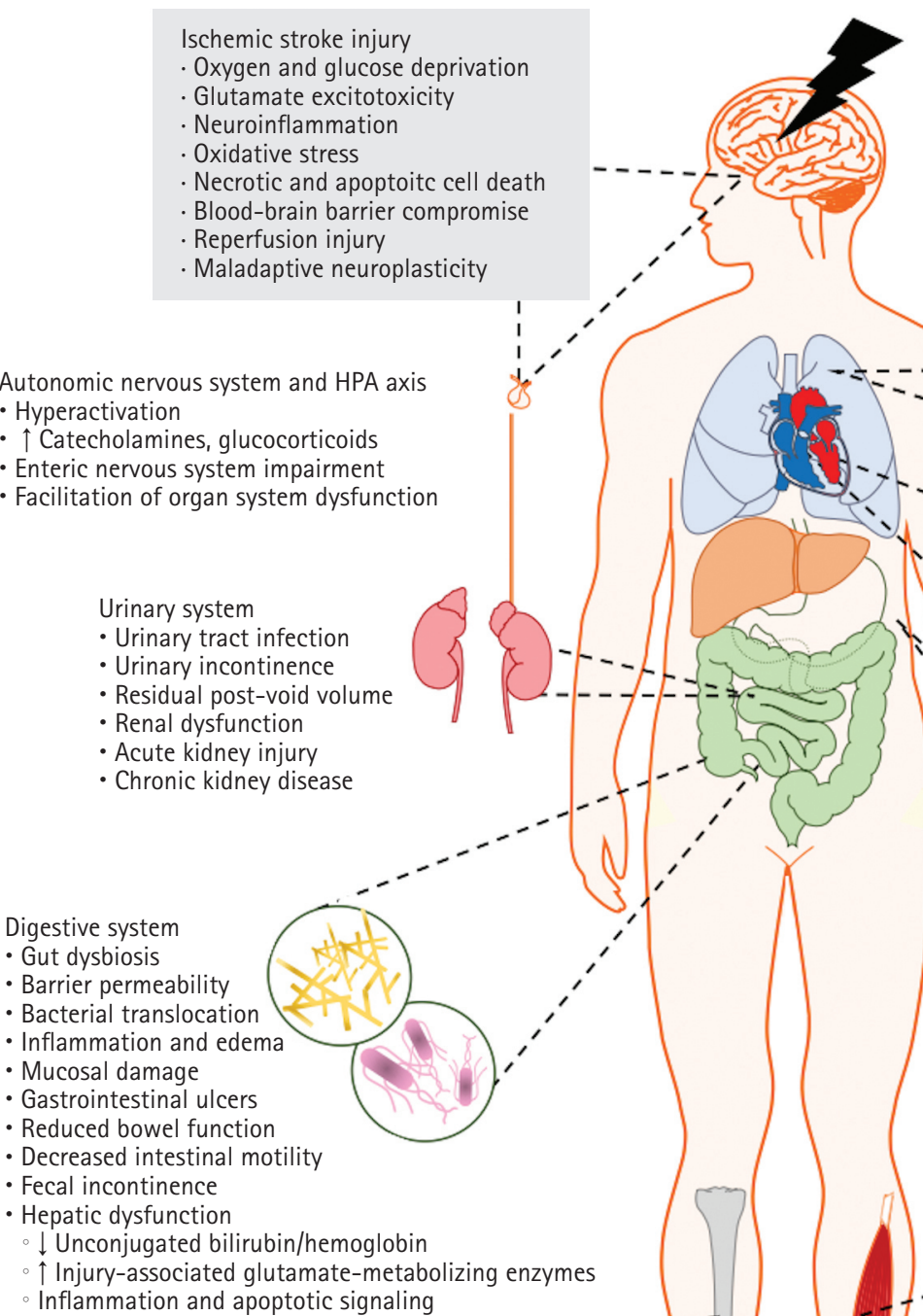

Endocrine system

- Pancreas:

- Insulin

- Hyperglycemia

- Impaired glucose tolerance

- Thyroid:

- $\downarrow$ Serum triiodothyronine

- Pineal:

- $\downarrow$ Melatonin

- Circadian rhythm disruption
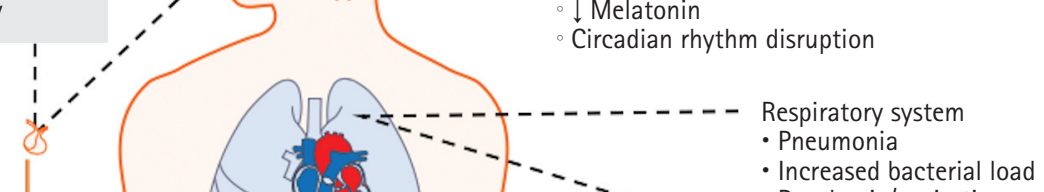

- Increased bacterial lo

- Venous thromboembolism

iton 
(Figure 2). ${ }^{12-14}$ These alterations are believed to be mediated by three overlapping mechanisms involving immune, autonomic, and motor pathways (Figure 3).

Shortly after AIS, a severe state of immunodepression is seen resulting in the high incidence of post-stroke infections. ${ }^{9,11}$ This post-stroke immunodepression is mediated by the autonomic and hypothalamic pituitary adrenal axis (HPA) activation and the interaction of the stroke-affected brain with the immune system through complement activation and release of damageassociated molecular patterns (DAMPs). ${ }^{15,16}$ Additionally, HPA activation is thought to be a critical channel through which multiple other systems are dysregulated, resulting in cardiac, renal, and gastrointestinal imbalances. Furthermore, motor pathway impairment secondary to AIS contributes to muscle wasting while the associated immobility increases the risk of deep vein thrombosis (DVT) and pulmonary embolism (PE) (Table 1). These factors overlap resulting in the worsening morbidity and mortality of AIS (Figure 3). In the following sections, these overlapping mechanisms and their subsequent clinical implications are discussed in further detail.

\section{Stroke-induced immunodepression}

Within hours of AIS, autonomic activation and release of DAMPs affect the various immune cells in the body. Immune cells from lymphoid populations in the spleen, gut-associated lymphoid tissue (GALT), and bone marrow reach brain vasculature and parenchyma. ${ }^{17,18}$ Together with resident microglia, the arriving neutrophils, monocyte/macrophages, and innate lymphocytes (e.g., natural killer [NK] cells) respond by producing proinflammatory mediators, after which $\mathrm{T}$ - and B-cell activation delivers its adaptive response. ${ }^{17-19}$ The roles of T-cell subsets have been thoroughly investigated, where pro-inflammatory T-helper (Th1), Th17, y $\delta$ T-cells, and cluster of differentiation 8+ (CD8+) T-cells promote initial tissue damage, enhance blood brain barrier breakdown, and contribute to neuronal apoptosis. ${ }^{19}$ Following this acute activation phase, an abrupt anti-inflammatory shift supervenes. This process is thought to be mediated by autonomic and neuroendocrine dysfunction, monocyte deactivation, and NK cell impairment that suppress immune activity. In addition, peripheral mobilization and apoptosis decrease blood lymphocyte counts by half. ${ }^{20}$ The shift toward anti-inflammatory Th2 cells and expansion of protective forkhead box protein P3+ (FoxP3+) regulatory T-cells (Tregs)

Table 1. Systemic complications of ischemic stroke

\begin{tabular}{|c|c|c|c|}
\hline Complication & Characterized by & Underlying pathophysiologies & Reference \\
\hline Infection & Commonly stroke-associated pneumonia, urinary tract infection & $\begin{array}{l}\text { Immunodepression, gut } \\
\text { dysbiosis, autonomic } \\
\text { activation, immobility }\end{array}$ & $\begin{array}{l}\text { P. }{ }^{15,20,27,35-37} \\
\text { C. }{ }^{8,24,34,43,44,47-49,52,5}\end{array}$ \\
\hline Pulmonary embolism & $\begin{array}{l}\text { Heightened VTE risk, resulting in DVT development and transfer to } \\
\text { pulmonary circulation }\end{array}$ & $\begin{array}{l}\text { Autonomic dysfunction, } \\
\text { immobility, coagulant } \\
\text { activation post-infection }\end{array}$ & C. ${ }^{100-102,111}$ \\
\hline Renal dysfunction & Low eGFR, incontinence, development of AKI/CKD/ESRD & $\begin{array}{l}\text { Sympathetic output, } \\
\text { inflammation }\end{array}$ & $\begin{array}{l}\text { P. }{ }^{112} \\
\text { C. }{ }^{76-79,113,114}\end{array}$ \\
\hline Cardiac dysfunction & $\begin{array}{l}\text { Cardiac arrhythmias, systolic dysfunction, ECG abnormalities, silent } \\
\text { myocardial ischemia, cardiac arrest, Takotsubo cardiomyopathy }\end{array}$ & $\begin{array}{l}\text { Sympathetic signaling, } \\
\text { vagal modulation }\end{array}$ & $\begin{array}{l}\text { P. }{ }^{7,62} \\
\text { C. } \\
10,57-61,63,64\end{array}$ \\
\hline Gastrointestinal concerns & $\begin{array}{l}\text { Intestinal muscosa damage, decreased gut motility, GI bleeds, } \\
\text { bowel dysfunction }\end{array}$ & $\begin{array}{l}\text { Autonomic dysfunction, } \\
\text { gut dysbiosis }\end{array}$ & $\begin{array}{l}\text { P. }{ }^{66} \\
\text { C. }{ }^{65,67}\end{array}$ \\
\hline Hepatic dysfunction & $\begin{array}{l}\text { Hepatic inflammatory/apoptotic activation, hepatic ketogenesis, } \\
\text { compromised hepatic insulin signaling, increased ER stress, } \\
\text { altered bilirubin/liver enzyme levels }\end{array}$ & $\begin{array}{l}\text { Catecholamine surge, } \\
\text { noradrenergic-mediated } \\
\text { innervation }\end{array}$ & $\begin{array}{l}\text { P. }{ }^{71-74} \\
\text { C. }{ }^{68}\end{array}$ \\
\hline Endocrine imbalance & $\begin{array}{l}\text { Decreased insulin release, hyperglycemia; decreased T3, thyroid } \\
\text { imbalance, reduced T3-related neuroprotection; decreased } \\
\text { melatonin, circadian shift and sleep disturbance, reduced } \\
\text { melatonin-related neuroprotection }\end{array}$ & $\begin{array}{l}\text { Sympathetic signaling; } \\
\text { inflammatory mediators, } \\
\text { glucocorticoids; autonomic } \\
\text { disruption }\end{array}$ & $\begin{array}{l}\text { P. }{ }^{84,85} \\
\text { C. }{ }^{80-83,86}\end{array}$ \\
\hline Musculoskeletal decline & $\begin{array}{l}\text { Bone loss, remodeling disorder, increased fracture risk, low BMD/ } \\
\text { BMC; repressed skeletal muscle repair, increased catabolic } \\
\text { activity, atrophy, altered inflammatory signaling, myofiber } \\
\text { phenotype shift, functional disability }\end{array}$ & $\begin{array}{l}\text { Sympathetic activation, } \\
\text { immobility }\end{array}$ & $\begin{array}{l}\text { P. } 13,104,105,107 \\
\text { C. }{ }^{103,109,115}\end{array}$ \\
\hline
\end{tabular}

P., preclinical studies; C., clinical studies; VTE, venous thromboembolism; DVT, deep vein thrombosis; eGFR, estimated glomerular filtration rate; AKI, acute kidney injury; CKD, chronic kidney disease; ESRD, end-stage renal disease; ECG, electrocardiography; GI, gastrointestinal; ER, endoplasmic reticulum; T3, triiodothyronine; $\mathrm{BMD}$, bone mineral density; $\mathrm{BMC}$, bone mineral content. 


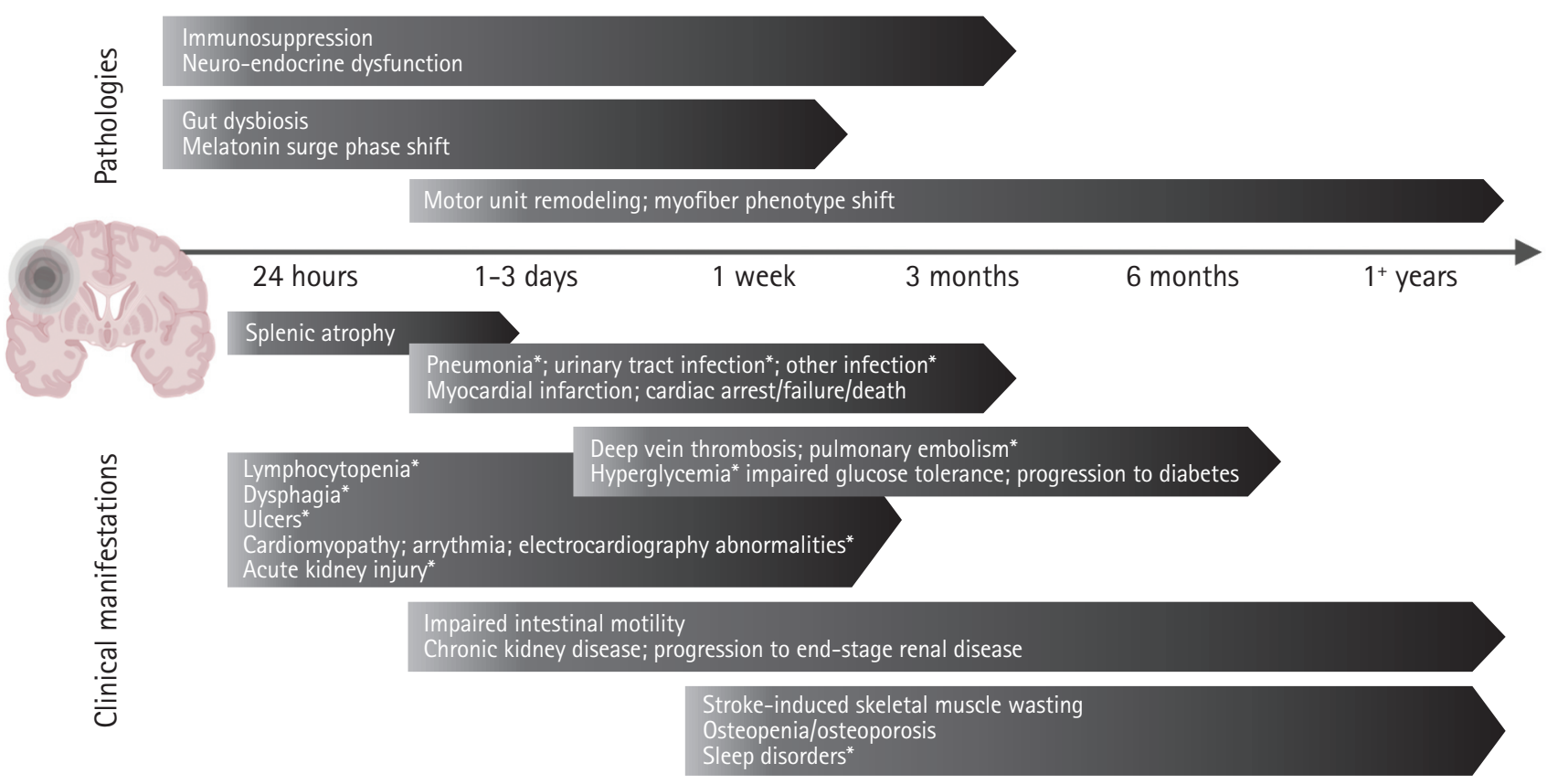

Figure 2. Timeline of systemic complications following stroke. Systemic responses to ischemic stroke present clinically within hours and continue developing well beyond hospital discharge. Though some are transient in nature, many complications progress chronically into the months and years that follow. This timeline summarizes the onset and evolution windows of clinical manifestations (e.g., pneumonia) and associated pathologies (e.g., immunosuppression). Brain graphic created with BioRender. *Denotes predictors of poor outcome.

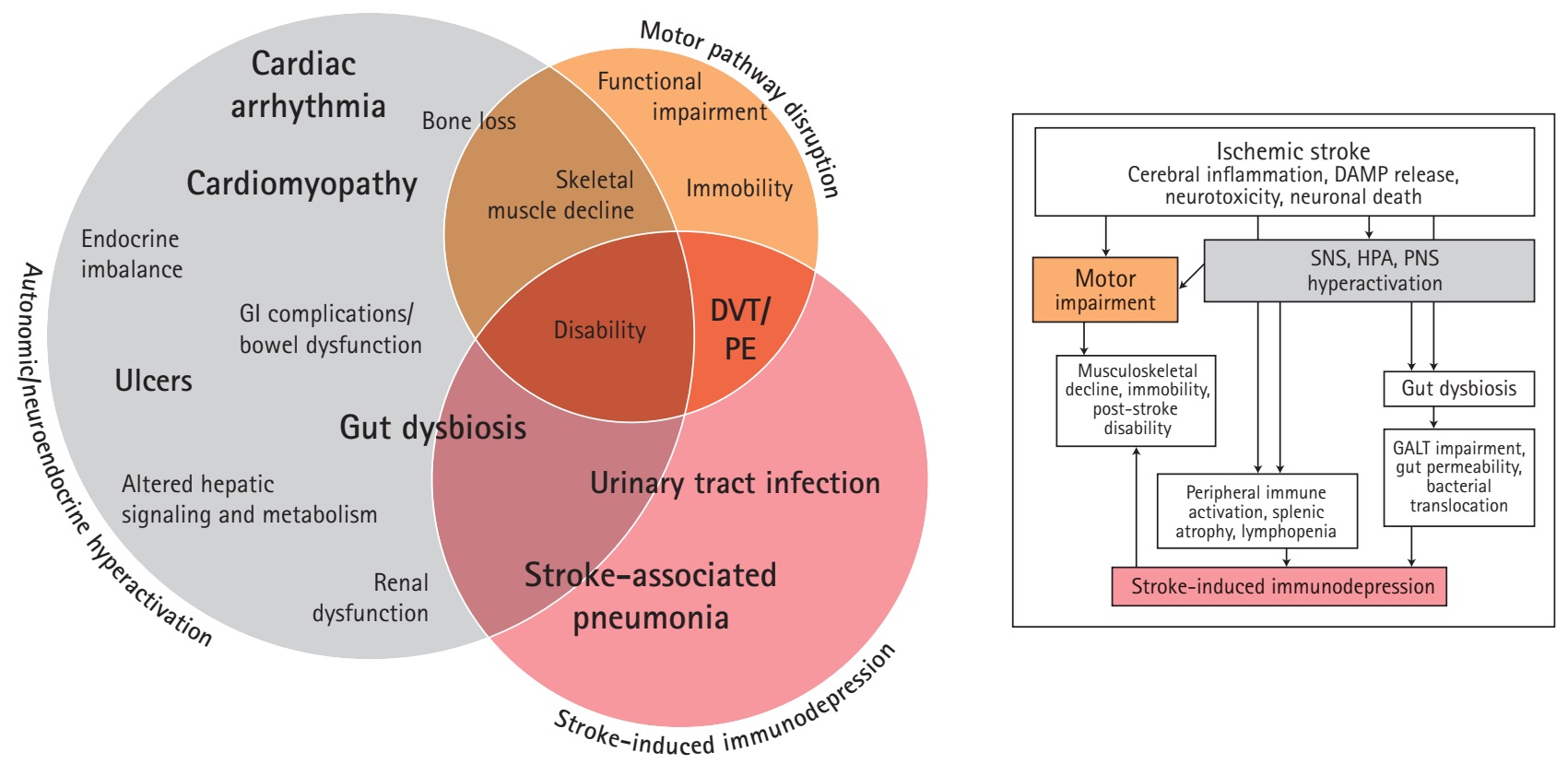

Figure 3. The pathophysiological sequelae of ischemic stroke. The impact of ischemic stroke reaches systemic proportions through evolution of three main pathophysiologies: stroke-induced immunodepression, autonomic and neuroendocrine dysfunction, and motor pathway disruption (flow chart). Each pathophysiology then facilitates development of the detrimental clinical complications observed beyond the stroke-affected brain (Venn diagram). Though much overlap exists between influential pathophysiologies and the ensuing complications, this figure presents a simplified overview of how the pathophysiological sequelae of ischemic stroke culminates in a vast array of clinical complications. Gl, gastrointestinal; DVT, deep vein thrombosis; PE, pulmonary embolism; DAMP, damage-associated molecular pattern; SNS, sympathetic nervous system; HPA, hypothalamic pituitary adrenal axis; PNS, parasympathetic nervous system; GALT, gut-associated lymphoid tissue. 
protect against further neuroinflammation. ${ }^{21}$ While limiting excessive immunological brain injury, the diminished immune capacity prevents sufficient inflammatory response to infection. ${ }^{15}$ Though exact mechanisms of prompt immune activation and opposing immunodepression are not fully understood, known participants in brain-immune communication after stroke are described below.

\section{DAMPs and endotoxin tolerance}

DAMPs are intracellular biomolecules that initiate an immune response upon release from necrotic cells. Upon detection by pattern recognition receptors on immune cells (e.g., receptor for advanced glycation end products [RAGE], toll-like receptors [TLRs]), DAMPs acutely amplify pro-inflammatory cytokine production. ${ }^{15}$ This disproportionately large immune reaction incites immature monocyte migration from bone marrow, proliferation of bone marrow-derived suppressor cells in the spleen, lymphopenia, and immune cell apoptosis. ${ }^{22,23}$ DAMP-induced exhaustion of monocyte function yields a state of endotoxin tolerance, a phenomenon that protects the stroke-affected brain from further damage but leaves immune cells unable to elicit adequate pro-inflammatory reaction to insult. ${ }^{8}$

Monocytes from AIS patients exhibit decreased surface expression of major histocompatibility complex (MHC) class II molecule human leukocyte antigen D related (HLA-DR) and consequently exist in a state of diminished antigen presentation..$^{24}$ Neuronal chromatin-associated nuclear protein highmobility group box 1 protein (HMGB1), a pivotal DAMP in stroke pathology, is elevated in serum within hours. ${ }^{15}$ Both markers of immunodepression, low MHC II and HLA-DR at post-stroke day one predicted infection up to 2 weeks later, ${ }^{24}$ while preclinical blocking of the HMGB1-RAGE pathway attenuated immunodepression and lymphocyte inactivation. ${ }^{22}$ Mitochondrial DAMPs are also markedly increased in plasma after stroke. Circulating mitochondrial DNA strongly correlated with the impaired response of refractory-state monocytes and infection. ${ }^{8}$ Furthermore, healthy monocytes cultured in stroke patient serum containing mitochondrial DNA exhibited the same refractory state. ${ }^{8}$

Invariant natural killer T (iNKT) cells are a unique group of innate immune cells that survey the blood for circulating immunogens. Recent data suggest iNKT cells in liver sinusoids detect and respond to brain injury. ${ }^{25}$ Following middle cerebral artery occlusion (MCAO), iNKT cells demonstrated decreased crawling activity specific to cerebral ischemia, as hindlimb ischemia-reperfusion had no effect on iNKT mobility. ${ }^{25}$ Poststroke changes to iNKT behavior also contribute to immunodepression and increased infection risk. While iNKT numbers were not altered by stroke-induced lymphopenia, activation marker CD69 increased in peripheral blood and liver iNKT populations after MCAO prior to the anti-inflammatory cytokine shift. Neutrophil infiltration, edema, and bacterial load also increased in the lungs within 24 hours, consistent with clinical outcomes. ${ }^{25}$

\section{Splenic volume and cell cycling}

The spleen is a lymphoid organ functioning in blood filtration and immune response. Preclinical stroke studies describe immediate decreases in splenic volume and T-cell antigen response. ${ }^{20,23}$ Similarly, stroke survivors experience splenic atrophy with re-expansion beginning after 48 hours. ${ }^{12}$ Prompted by sympathetic hyperactivation, contributors to splenic contraction include immune cell release followed by apoptosis of lymphocyte subsets: B-, T-, and NK cells. . $^{16,20,26}$ Confirming the impact of apoptosis in immunodepression, experimental treatment with systemic caspase inhibitor quinolyl-valyl-0-methylaspartyl-[-2,6-difluorophenoxy]-methyl ketone (Q-VD-OPH) minimized stroke brain injury, improved splenocyte survival, and reduced bacteremia. ${ }^{27}$

To delineate the spleen's role in stroke injury, independent preclinical studies showed splenectomy either 2 weeks before $M C A O^{28}$ or in the immediate hours afterward ${ }^{29}$ decreased infarct volume and neurological deficits. Interestingly, splenectomy immediately before stroke induction did not improve infarct volume or neuroimmune response, ${ }^{17,30}$ though variance in stroke model, post-operative recovery, and immune compensation warrant further investigation. ${ }^{10,30}$

\section{Gut dysbiosis}

The microbial population in the intestinal tract interacts with specialized GALT to regulate T-cell homeostasis and establish the maturing immune system. Disruption of the intestinal microbiome, or gut dysbiosis, is observed following AIS. ${ }^{14}$ Because microbial metabolites influence immune polarization, gut dysbiosis affects intestinal lymphocyte populations. ${ }^{31}$ Due to its role in immune response and systemic inflammation, gut dysbiosis is addressed in the context of neuroimmune dysregulation.

In response to inflammatory stress and altered vagal communication with the intestinal tract, gut dysbiosis after stroke is characterized by a reduction in species diversity, imbalance in phyla predominance, and altered metabolite production. ${ }^{14,32}$ Preclinically, dysbiosis directly primed inflammatory $\gamma \delta$ T-cells in the gut, which then trafficked to the brain and exacerbated stroke evolution. ${ }^{31}$ Recolonizing germ-free mice with dysbiotic bacteria from stroke-affected mice yielded larger lesions and deficits after MCAO, while healthy fecal transplantation normalized microbiota, reduced infarct size, and attenuated pro- 
inflammatory T-cell polarization. ${ }^{14}$ Following the post-stroke immunosuppressive shift, mesenteric lymph node dendritic cells prompt migration of protective Tregs to the gut to decrease $\gamma \delta$ T-cell movement to the brain. ${ }^{19}$ Compared to mice with less severe dysbiosis, mice with excessive dysbiosis had significantly more $\gamma \delta$ T-cells, fewer Tregs, larger infarcts, and greater neurological deficits. ${ }^{33}$

Clinically, AIS patients presented with altered fecal bacterial counts and organic acid levels, as well as disrupted biomarkers of metabolism and inflammation. ${ }^{32}$ Gut microflora are further disturbed by antibiotic administration for infection control. ${ }^{34}$ Intestinal edema and inflammation after experimental stroke compromised mucosal barrier function and may enable bacterial translocation to various organs. ${ }^{35}$ Indeed, bacteremia occurred acutely following rodent stroke ${ }^{34}$ and was observed in AIS patients at admission. ${ }^{14}$ Microbes detected in the lungs originated in the host's small intestine, with translocation to the spleen, liver, and mesenteric lymph nodes as early as 24 hours. ${ }^{34,35}$ These findings indicate gut dysbiosis is both a consequence of and subsequent contributor to stroke pathophysiology, though a clinical link between dysbiosis and stroke outcomes remains to be established.

\section{The systemic consequences of stroke-induced immunodepression}

The critical suppression of the immune system manifests clinically as infection, including stroke-associated pneumonia (SAP) and urinary tract infection (UTI), the most frequently encountered complications in stroke patients. ${ }^{36}$

\section{Stroke-associated pneumonia}

Murine studies report increased bacterial load in lungs and peripheral blood by 24 hours post-MCAO.$^{20}$ Obstructing sympathetic activity with a $\beta$-blocker, however, prevented bacterial infection and reduced mortality highlighting the role of sympathetic system activation. ${ }^{20,37}$ Immunodepression was further demonstrated using Streptococcus pneumoniae exposure: while 200,000 colony-forming units (CFUs) were required to cause pneumonia in sham animals, only 200 CFUs were necessary in stroke mice, again preventable with sympathetic blockade. ${ }^{37}$ Marked lymphopenia was prevented through glucocorticoid receptor blockage, while both HPA and sympathetic inhibition protected against lymphocyte apoptosis. ${ }^{18}$

Stroke-induced parasympathetic stimulation is widely accepted as another contributor to infection through initiation of anti-inflammatory pathways. ${ }^{14,38,39}$ Vagal signaling and cholinergic activation target a7-nicotinic acetylcholine receptors (a7-nAChR) across cell types, including lung epithelial cells and resident immune alveolar macrophages. ${ }^{40}$ Mice after MCAO presented with significant parasympathetic response and pneumonia, while vagotomy or a7-nAChR-deficiency maintained pulmonary immune defense and prevented SAP.40

Clinically, SAP is a major complication of AIS affecting onethird of patients. ${ }^{41}$ In contrast to preclinical data, human studies utilizing $\beta$-blockers to address infection report mixed outcomes, from protective ${ }^{42}$ to unfavorable. ${ }^{43}$ Aspiration is another important mechanism of SAP, though prevention measures alone do not eliminate infection. Indeed, a multi-center study established dysphagia and immunodepression as independent predictors of SAP. ${ }^{24}$ Dysphagia correlated with SAP only in patients with low monocytic HLA-DR, suggesting screening for both dysphagia and immunosuppression could identify SAP risk. ${ }^{24}$ Though SAP is linked to functional decline and mortali$\mathrm{ty}_{1}{ }^{36}$ prophylactic administration of antibiotics failed to improve either outcome in clinical trials. ${ }^{44,45}$ This emphasizes the knowledge gap regarding complex pathophysiological mechanisms of post-stroke immunodepression and the fragile lung-brain axis.

\section{Urinary tract infection}

AIS severity is an independent predictor of UTI ${ }^{41}$ which is in turn associated with worse outcomes, longer hospital stays, and poor discharge outcome. ${ }^{41}$ Despite lowering UTI frequency, prophylactic antibiotics did not benefit functional outcome or reduce mortality in clinical trials similar to SAP. ${ }^{46}$ Risk factors include catheter use, incontinence, and post-void residual urine volume ${ }^{47}$ though high rates of UTI have been reported in patient cohorts both with (50\%) and without (24\%) indwelling catheters. ${ }^{48}$ Programs that prompted routine assessment, stop orders, or early removal reduced catheter duration and incidence of UTI ${ }^{49}$ as did measuring post-void urine volume with portable bladder ultrasound. ${ }^{47}$ Antimicrobial or antibiotic-impregnated catheters have been shown to delay or prevent bacteriuria, but evidence of UTI reduction is scarce ${ }^{50}$ and highlights immune system complexity after stroke.

\section{Autonomic and neuroendocrine dysregulation}

Dysregulation of autonomic and HPA systems has widespread effects on all body organs (Figure 3). The mechanisms by which the autonomic system communicates with the peripheral immune system have been most thoroughly investigated and will be discussed in depth first.

\section{Sympathetic hyperactivation}

The pro-inflammatory cytokine surge after AIS activates the 
sympathetic nervous system (SNS), triggering catecholamine production at the adrenal medulla and sympathetic nerve terminals. ${ }^{20}$ This initiates immune cells mobilization, stimulates their apoptosis, and inhibits further cytokine production. ${ }^{20} \mathrm{Mu}$ rine studies identified sympathetic activation as the direct cause of spontaneous bacterial infection after stroke, ${ }_{1}^{20}$ while pharmacological inhibition of splenic adrenergic receptors reduced infarct volume, preserved splenic weight, and protected against high bacterial load. ${ }^{51}$ Though splenectomy was protective, denervation alone did not alter splenic weight or infarct volume ${ }^{51}$ suggesting a regulatory role for circulating catecholamines over direct sympathetic innervation. Indeed, patients with post-stroke infection presented first with increased catecholamine levels. ${ }^{52}$

On the other hand, noradrenergic-mediated innervation, rather than humoral input, is responsible for post-stroke iNKT behavior. Direct injection of norepinephrine into livers of shamoperated mice mimicked the immunosuppressive iNKT response to stroke and increased infection risk, whereas $\beta$-adrenergic receptor inhibition or reduction of hepatic noradrenergic nerve terminals attenuated the MCAO-induced immunosuppressive shift in mice, ${ }^{25}$ similar to results in the spleen. ${ }^{51}$

\section{HPA axis dysregulation}

HPA axis overactivation releases glucocorticoids from the adrenal cortex, promoting the immunosuppressive shift to anti-inflammatory cytokine production. ${ }^{20}$ Glucocorticoids have been shown to impede pro-inflammatory cytokine production as well, and stunt immune cell proliferation to promote apoptosis. ${ }^{53}$ Clinically, AIS prompts an abrupt increase in cortisol, which is linked to post-stroke infection, mortality, and functional dependence. ${ }^{54}$ Experimental blocking of glucocorticoid receptors prevented the immunosuppressive stroke-associated Iymphopenia. ${ }^{18,20}$ Many studies report diurnal pattern disruption of cortisol after stroke, though full implications of the shift remain unknown. ${ }^{54}$

\section{Parasympathetic vagal activation}

The parasympathetic nervous system is involved with neuroimmune regulation following stroke through inflammatory stimulation of the vagus nerve. ${ }^{40}$ The subsequent release of acetylcholine activates a7-nAChR, triggering the vagal cholinergic anti-inflammatory pathway ${ }^{55}$ which inhibits pro-inflammatory macrophage activity. Studies employing vagal stimulation ${ }^{38}$ and a7-nAChR agonists ${ }^{39}$ confirm vagal/a7-nAChR involvement in reducing cerebral inflammation. The other consequence of the parasympathetic vagal activation is its effect on the brain and peripheral NK cell regional population in mice and patients. ${ }^{26} \mathrm{~A}$ decrease-then-recovery of NK counts occurred in the periphery, but the opposite-initial increase, then subsequent contraction-was observed in the brain. In addition, cholinergic exposure suppressed NK function in the brain but not in the periphery. ${ }^{26}$ This suggests compartment-specific mechanisms may be ideal targets for preventing immunodepression in the periphery while leaving the protective shift in the brain undisturbed.

\section{The systemic consequences of autonomic/ neuroendocrine dysregulation}

Overstimulation of sympathetic, HPA, and parasympathetic pathways mediates the systemic disease progression, prompting a clinical cascade of cardiac, gastrointestinal, hepatic, renal, and endocrine complications.

\section{Cardiovascular dysfunction}

Stroke severity, disability, and mortality are higher in patients with lower cardiac function. ${ }^{56,57}$ Conversely, AIS induces cardiac dysfunction without prior risk factors or pre-existing heart disease. ${ }^{57,58}$ This manifests with electrocardiographic abnormalities, elevated serum cardiac troponin $T$ in the absence of myocardial infarction, depressed cardiac function in the acute phase, or severe complications such as arrhythmias or cardiac arrest. $^{56-58}$ Incidentally, $19 \%$ of AIS patients had a serious or fatal cardiac event in the first 3 months. ${ }^{10}$

Takotsubo cardiomyopathy (TC) is a stress-induced transient weakening and ballooning of the left ventricle that is seen in a subset of AIS patients. Commonly asymptomatic, TTC may mimic myocardial infarction in injury biomarkers and electrocardiography and is associated with insular infarcts and poor outcomes. ${ }^{59,60}$ Heart function typically returns to normal over several weeks, but severe cases increase risk for cardiac embolism, respiratory failure, and death. ${ }^{59}$

Cardiac dysfunction following AIS has been attributed to sympathetic and parasympathetic imbalance. One study confirmed overstimulation of cardiac sympathetic innervation using the catecholamine synthesis rate-limiting enzyme tyrosine hydrolase. 7 Sympathetic hyperstimulation also blunts vagal influence, as confirmed in stroke patients via heart rate variability testing. ${ }^{61}$ HPA activation and hypothalamic paraventricular nucleus output also prompted cardiac arrhythmias and impaired cardiac output in rat models. ${ }^{62}$ Brain regions of cardiovascular interest are the brainstem (e.g., rostral ventrolateral medulla) and insular cortex. The laterality hypothesis maintains left and right insular cortices control cardiac parasympathetic and sympathetic activity respectively, and while patient studies indicate heightened severity of cardiac dysfunction with insular strokes, 
presentation and degree of laterality remain controversial. ${ }^{63,64}$

\section{Gastrointestinal and metabolic impairments}

Autonomic dysfunction impairs enteric communication and, consequently, gastrointestinal function. Additional contributors include inactivity, diet, and various medications. ${ }^{65}$ Preclinical and clinical studies alike report bowel dysfunction and gastrointestinal impairment after stroke. ${ }^{14}$ Reduced intestinal motility results in constipation and new-onset fecal incontinence in up to half of AIS patients. ${ }^{65}$ Rodent studies identified histological damage, gastric edema, hyperemia, altered cellular composition, and hemorrhagic erosion of the gastric mucosa after stroke, ${ }^{66}$ which present clinically as ulcers ${ }^{67}$ Acid-suppressive therapy may reduce gastrointestinal bleeding ${ }_{1}^{67}$ but the underlying intestinal inflammation, gut dysbiosis, and autonomic contributors remain.

Metabolic homeostasis in the liver is impaired after AIS and correlates with infarct volume. ${ }^{68}$ Stroke is associated with reduced unconjugated bilirubin and hemoglobin levels at admis$\operatorname{sion}^{68}$ while increasing glutamate-metabolizing enzymes associated with liver injury (e.g., glutamate oxaloacetate transaminase [GOT]), a possible prompt for peripheral glutamate metabolism in response to glutamate release from the ischemic brain. ${ }^{68}$ Plasma and neuronal sources of GOT support scavenging $^{69}$ and excitotoxic glutamate metabolism ${ }^{70}$ after AIS respectively, though post-stroke implications of hepatic GOT are yet to be revealed. Additionally, experimental stroke promoted inflammation, DNA fragmentation, and apoptotic signaling in the liver through kinase activation (i.e., c-JUN N-terminal kinases [JNKs], extracellular signal-regulated kinases [ERKs]. ${ }^{71}$ Compromised hepatic insulin signaling, increased expression of gluconeogenic genes, and increased endoplasmic reticulum stress have been reported in the liver and are attributed to the post-stroke catecholamine surge. ${ }^{72}$

Hepatic ketogenesis is another hepatic disturbance seen in animal models. Stroke-affected mice develop ketogenesis when fed fat-rich diet, even when the diet was not sufficient to trigger ketosis pre-stroke. ${ }^{73}$ This phenomenon may have a potential role in angiogenesis and neuroprotection following AIS. $^{74}$

\section{Kidney dysfunction}

Stroke-induced autonomic hyperactivation brings an increase in sympathetic activity and systemic inflammation, disrupting renal homeostasis. ${ }^{75}$ Up to one-third of stroke patients experience renal impairment during hospital stay. ${ }^{76}$ AIS patients can develop acute kidney injury, defined as decreased urine output or increased absolute serum creatinine within 48 hours. ${ }^{77}$ Influential factors beyond sympathetic activity include hydration status, contrast nephrotoxicity, and vascular intervention. ${ }^{77}$ Stroke survivors can also suffer progression of chronic kidney disease that can evolve to end stage renal disease. ${ }^{78}$ Poststroke renal dysfunction upon hospitalization is a prognostic indicator of mortality at 10 years ${ }^{76}$ and thus supports the case for identification and management.

Other disturbances include urinary incontinence, with or without urgency, in half of AIS patients. Given the complex neurological control over micturition, lesion size may be of greater concern than specific localization to certain brain areas. ${ }^{79}$

\section{Endocrine imbalance}

Stroke-induced sympathetic signaling to the pancreas blocks insulin release, making hyperglycemia common after stroke even in non-diabetic patients. ${ }^{80}$ Hyperglycemia commonly extends beyond the acute period to involve impaired glucose tolerance at discharge or progression to diabetes. ${ }^{80}$ While hyperglycemia is associated with larger infarcts and worse functional outcome, clinical trials found no therapeutic benefit to intensive blood glucose control, noting induced hypoglycemia is of equal concern. ${ }^{81}$

Low levels of thyroid hormone triiodothyronine (T3) have been observed immediately following stroke in more than half of patients, independent of pre-existing thyroid conditions. ${ }^{82}$ Low serum $T 3$ and positive thyroid autoantibodies were associated with worse outcomes following AIS. ${ }^{82,83}$ Experimental T3 administration after MCAO reduced cerebral edema by inhibiting aquaporin-4 (AQP4) expression, ${ }^{84}$ but clinical T3 supplementation has not been tested. Possible explanations of thyroid hormone disruption after AIS include pro-inflammatory mediators and glucocorticoid influence. ${ }^{82}$

Stroke disrupts the circadian rhythms and melatonin production, even when lesions do not affect pineal gland control. ${ }^{85} \mathrm{~A}$ preclinical study observed a phase shift in melatonin release after stroke ${ }_{1}^{85}$ and clinical AIS studies reported decreased melatonin at day $1 .^{86}$ Melatonin treatment was neuroprotective after rodent stroke, where proposed mechanisms are mitochondrial apoptosis pathway inhibition and promotion of neuronal survival pathways ${ }_{1}^{87}$ suggesting the melatonin decrease following stroke may be from swift metabolism to combat stroke-induced damage.

\section{Motor pathway disruption}

Focal weakness as a result of motor pathway disruption is commonly seen post-AIS. ${ }^{1,2,5}$ In addition to the motor system lesion, the pathophysiology of motor impairment stems also from the neuroplastic response, which alters upstream/down- 
stream non-lesioned networks. ${ }^{88}$ Neuroimaging advancements (e.g., functional magnetic resonance imaging) foster detailed study of motor mapping after stroke. ${ }^{89}$ Stroke patient testing found functional coupling between cortical activity and muscle output is markedly reduced in the acute phase and remains as such even when motor performance improves. ${ }^{90}$ Interestingly, patients without apparent improvement still exhibited complex changes over time due to motor network connectivity. ${ }^{91}$ Investigated mechanisms of motor functional recovery include axonal sprouting, ${ }^{92,93}$ white matter repair, ${ }^{94}$ neurogenesis, ${ }_{1}^{95}$ and ipsilesional/contralesional network reorganization. ${ }^{96}$ Just as consequences of stroke disability maladaptively alter cortical mapping and hinder recovery, ${ }^{97}$ interventions targeting beneficial neuroplastic reorganization can strengthen tracts and improve recovery..$^{98,99}$

\section{Systemic consequences of motor pathway disruption and immobility}

Motor pathway disruption and secondary immobility result in increased risk of venous thromboembolism (VTE) formation and widespread impacts to the musculoskeletal system.

\section{Deep vein thrombosis and pulmonary embolism}

Post-stroke VTE risk ranges from $8 \%$ to $30 \%$ and is independently associated with AIS severity. ${ }^{1,100,101}$ Especially in the acute phase when hemodynamics, inflammation, and immobility compound, DVT may develop and travel to the lungs, yielding life-threatening PE. ${ }^{100}$ Atherosclerotic predisposition was explored as a potential link between AIS and VTE, but causation was determined unlikely. ${ }^{101}$ Infection, however, is associated with both coagulation system activation and immobilization. ${ }^{101}$ As such, stroke-associated infection, prothrombotic activity, inflammation, dehydration, and immobility all serve roles in VTE development after stroke. ${ }^{101}$ Prophylactic chemical DVT dosages and intermittent pneumatic compression reduce DVTs in AIS patients. ${ }^{4,102}$

\section{Bone loss and remodeling disorder}

Chronic stroke patients experience bone loss as mineral density declines significantly within one year and fracture risk increases up to 7-fold. ${ }^{103}$ The pathophysiology of bone loss extends beyond immobility and asymmetric weight-bearing to disruption of central brain centers controlling skeletal homeostasis. ${ }^{104}$ Inner ear vestibular lesioning in rats decreased bone formation without affecting resorption or locomotor activity: ${ }_{i}^{104}$ these alterations in bone metabolism were attributed to SNS outflow and prevented with $\beta 2$-adrenergic receptor blockade. ${ }^{104}$ Likewise, serum bone formation marker $\mathrm{N}$-terminal propeptide of type 1 procollagen (PINP) decreased independent of activity level in MCAO rats, with no change in resorption marker C-terminal telopeptide of type I collagen (CTX). ${ }^{105}$ Further investigation is needed to define exact pathways involved with brain control of bone metabolism and stroke-induced remodeling disorders.

\section{Skeletal muscle decline}

Stroke prompts severe alterations to skeletal muscle tissue. Myofiber analysis identified a shift in myosin heavy chain predominance toward fast-twitch isoforms with initial denervation that declined as motor recovery and spasticity progressed. ${ }^{106}$ Reduced gait speed is also associated with the poststroke atrophy response. ${ }^{106}$ Catabolic activity in mouse strokeaffected muscle was measured as increased expression of apoptotic and proteasome proteolytic markers and significantly correlated with infarct size. ${ }^{107}$ Proposed contributors to skeletal muscle decline after stroke include reduced feeding and inactivity, sympathetic activation, and infection. Weight loss and muscle wasting, however, were not altered by high-caloric diet, sympathetic blockade, or antibiotic treatment, ${ }_{1}^{107}$ suggesting mechanisms unique to stroke are responsible for the observed pathophysiology.

Exact molecular mechanisms of AIS-induced muscular decline are unclear. Myostatin is upregulated in post-stroke paretic muscle. ${ }^{13,108}$ Myostatin inhibits the anabolic Akt/mammalian target of rapamycin (mTOR) pathway while increasing ubiquitin-proteasome activity and autophagy-lysosome proteolysis. ${ }^{108}$ Inhibiting myostatin with PINTA745 promoted recovery of muscle mass and function in rodents. ${ }^{108}$ Providing similar results, progressive resistance training decreased patient myostatin mRNA and stimulated muscle hypertrophy. ${ }^{109}$ Separately, stroke upregulated pro-inflammatory interferon- $\gamma$-induced protein 10 (IP-10/CXCL10) in rat paretic muscle while prompting significant loss of brain-derived neurotrophic factor (BDNF), an important mediator for muscular repair. ${ }^{13}$

Data propose the systemic inflammatory response following AIS reaches skeletal muscle and influences its reparative capacity. Clinical data regarding muscle pathophysiology and associated mechanisms are limited and identifies a need for evidence-based models of rehabilitation that address stroke-induced skeletal muscle decline.

\section{Conclusions and future directions}

A growing body of evidence recognizes acute and chronic repercussions in peripheral tissues that worsen stroke evolution and alter prognosis (Figures 1 and 4). The aforementioned ramifications of ischemic stroke on autonomic, neuroendocrine, 
Key points:

- The stroke-affected brain elicits wide-spread end organ dysfunction.

Associated clinical manifestations arise via three overlapping major pathophysiological mechanisms:

> autonomic and neuroendocrine hyperactivation

' stroke-induced immunodepression

> disruption of central motor pathways

Repercussions of stroke in the periphery worsen infarct evolution

and functional outcome.

- An integrative progression in the future of stroke research will:

> address the complexity of systemic stroke pathophysiologies

> resist reductionist approaches to target organ systems in isolation

s consolidate knowledge across clinical and translational specialties to inform comprehensive therapeutics

Figure 4. Ischemic stroke: a systemic disease overview. An overview of the key points, as detailed in this review, is presented in a summary box.

immune, and motor systems are a conduit for injury response to move beyond the CNS. As presented herein, the individual clinical manifestations of AIS cannot simply be attributed to a single pathophysiological mechanism. Rather, each complication stems from a myriad of influencers and, likewise, prompts new deficits while magnifying the existing disease state.

The disappointing translational failure of AIS therapeutics and neuroprotective agents from bench to bedside is markedly pronounced in comparison to clinical trial successes across various other medical conditions. ${ }^{110}$ This is partly related to the widespread complex pathophysiology of AIS in the body. Central to this issue is a call for integrative progression in stroke research, where experts consolidate therapeutic knowledge to address the complexity of stroke pathophysiology.

The concept of AIS as a systemic disease is clear when considering how pathophysiological mechanisms reach nearly every organ system in the human body. Hence, reductionist approaches that fail to consider bidirectional crosstalk between the CNS and periphery limit our ability to conceptualize new paradigms of patient care. A comprehensive understanding of post-stroke systems biology offers new direction to mechanistic discovery, defining multi-system targets to include the SNS, gut microbiome, neuroimmune interactions, and musculoskeletal metabolism. As such, collaborative research efforts across clinical specialties are necessary to inform methods and achieve the future of integrative stroke therapeutics.

\section{Supplementary materials}

Supplementary materials related to this article can be found online at https://doi.org/10.5853/jos.2019.02978.

\section{Disclosure}

The authors have no financial conflicts of interest.

\section{Acknowledgments}

This work was supported by American Heart Association Grant 19PRE34380992 (Maria H.H. Balch).

\section{References}

1. Benjamin EJ, Muntner $P$, Alonso A, Bittencourt MS, Callaway CW, Carson AP, et al. Heart disease and stroke statistics-2019 update: a report from the American Heart Association. Circulation 2019;139:e56-e528.

2. GBD 2016 Stroke Collaborators. Global, regional, and national burden of stroke, 1990-2016: a systematic analysis for the Global Burden of Disease Study 2016. Lancet Neurol 2019;18: 439-458.

3. Pierot L, Jayaraman MV, Szikora I, Hirsch JA, Baxter B, Miyachi $S$, et al. Standards of practice in acute ischemic stroke intervention: international recommendations. J Neurointerv Surg 2018;10:1121-1126.

4. Powers WJ, Rabinstein AA, Ackerson T, Adeoye OM, Bambakidis NC, Becker K, et al. 2018 Guidelines for the early management of patients with acute ischemic stroke: a guideline for healthcare professionals from the American Heart Association/American Stroke Association. Stroke 2018;49:e46-e110.

5. Platz T. Evidence-based guidelines and clinical pathways in stroke rehabilitation: an international perspective. Front Neurol 2019;10:200.

6. Xiong $X Y$, Liu L, Yang $\mathrm{QW}$. Refocusing neuroprotection in cerebral reperfusion era: new challenges and strategies. Front Neurol 2018:9:249.

7. Bieber M, Werner RA, Tanai E, Hofmann U, Higuchi T, Schuh $\mathrm{K}$, et al. Stroke-induced chronic systolic dysfunction driven by sympathetic overactivity. Ann Neurol 2017;82:729-743.

8. Hernández-Jiménez $E_{1}$ Gutierrez-Fernández $M$, Cubillos-Zapata C, Otero-Ortega L, Rodríguez-Frutos B, Toledano V, et al. Circulating monocytes exhibit an endotoxin tolerance status after acute ischemic stroke: mitochondrial DNA as a putative explanation for poststroke infections. J Immunol 2017;198:2038-2046.

9. Hannawi Y, Hannawi B, Rao CP, Suarez Jl, Bershad EM. Stroke-associated pneumonia: major advances and obstacles. Cerebrovasc Dis 2013;35:430-443.

10. Prosser J, MacGregor L, Lees KR, Diener HC, Hacke W, Davis 
$S$, et al. Predictors of early cardiac morbidity and mortality after ischemic stroke. Stroke 2007;38:2295-2302.

11. Dirnagl U, Klehmet J, Braun JS, Harms H, Meisel C, Ziemssen T, et al. Stroke-induced immunodepression: experimental evidence and clinical relevance. Stroke 2007;38(2 Suppl):770-773.

12. Chiu NL, Kaiser B, Nguyen $\mathrm{W}$, Welbourne $S$, Lall $C$, Cramer $\mathrm{SC}$. The volume of the spleen and its correlates after acute stroke. J Stroke Cerebrovasc Dis 2016;25:2958-2961.

13. Sen CK, Khanna S, Harris $H$, Stewart $R$, Balch $M$, Heigel $M$, et al. Robot-assisted mechanical therapy attenuates stroke-induced limb skeletal muscle injury. FASEB J 2017;31:927-936.

14. Singh V, Roth S, Llovera G, Sadler R, Garzetti D, Stecher B, et al. Microbiota dysbiosis controls the neuroinflammatory response after stroke. J Neurosci 2016;36:7428-7440.

15. Kim ID, Lee $H$, Kim SW, Lee HK, Choi J, Han PL, et al. Alarmin HMGB1 induces systemic and brain inflammatory exacerbation in post-stroke infection rat model. Cell Death Dis 2018; 9:426.

16. Offner $H$, Subramanian $S$, Parker SM, Afentoulis ME, Vandenbark $A A$, Hurn PD. Experimental stroke induces massive, rapid activation of the peripheral immune system. J Cereb Blood Flow Metab 2006;26:654-665.

17. Kim E, Yang J, Beltran CD, Cho S. Role of spleen-derived monocytes/macrophages in acute ischemic brain injury. $J$ Cereb Blood Flow Metab 2014;34:1411-1419.

18. Mracsko E, Liesz A, Karcher S, Zorn M, Bari F, Veltkamp R. Differential effects of sympathetic nervous system and hypothalamicpituitary-adrenal axis on systemic immune cells after severe experimental stroke. Brain Behav Immun 2014;41:200-209.

19. Arya AK, Hu B. Brain-gut axis after stroke. Brain Circ 2018;4: 165-173.

20. Prass K, Meisel C, Höflich C, Braun J, Halle E, Wolf T, et al. Stroke-induced immunodeficiency promotes spontaneous bacterial infections and is mediated by sympathetic activation reversal by poststroke T helper cell type 1-like immunostimulation. J Exp Med 2003;198:725-736.

21. Offner $H$, Subramanian $S$, Parker SM, Wang $C$, Afentoulis ME, Lewis $A$, et al. Splenic atrophy in experimental stroke is accompanied by increased regulatory T cells and circulating macrophages. J Immunol 2006;176:6523-6531.

22. Liesz A, Dalpke A, Mracsko E, Antoine DJ, Roth S, Zhou W, et al. DAMP signaling is a key pathway inducing immune modulation after brain injury. J Neurosci 2015;35:583-598.

23. Santos Samary C, Pelosi P, Leme Silva P, Rieken Macedo Rocco P. Immunomodulation after ischemic stroke: potential mechanisms and implications for therapy. Crit Care 2016;20:391.

24. Hoffmann S, Harms H, Ulm L, Nabavi DG, Mackert BM, Schmehl I, et al. Stroke-induced immunodepression and dysphagia independently predict stroke-associated pneumonia: the PREDICT study. J Cereb Blood Flow Metab 2017;37:36713682.

25. Wong $\mathrm{CH}_{\text {, Jenne }} \mathrm{CN}$, Lee $\mathrm{WY}$, Léger $\mathrm{C}$, Kubes P. Functional innervation of hepatic iNKT cells is immunosuppressive following stroke. Science 2011;334:101-105.

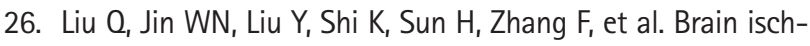
emia suppresses immunity in the periphery and brain via different neurogenic innervations. Immunity 2017;46:474-487.

27. Braun JS, Prass K, Dirnagl U, Meisel A, Meisel C. Protection from brain damage and bacterial infection in murine stroke by the novel caspase-inhibitor Q-VD-OPH. Exp Neurol 2007;206:183-191.

28. Ajmo CT Jr, Vernon DO, Collier L, Hall AA, Garbuzova-Davis S, Willing $A$, et al. The spleen contributes to stroke-induced neurodegeneration. J Neurosci Res 2008;86:2227-2234.

29. Belinga VF, Wu GJ, Yan FL, Limbenga EA. Splenectomy following MCAO inhibits the TLR4-NF-KB signaling pathway and protects the brain from neurodegeneration in rats. $J$ Neuroimmunol 2016;293:105-113.

30. Zierath D, Shen A, Stults A, Olmstead T, Becker KJ. Splenectomy does not improve long-term outcome after stroke. Stroke 2017;48:497-500.

31. Benakis C, Brea D, Caballero S, Faraco G, Moore J, Murphy M, et al. Commensal microbiota affects ischemic stroke outcome by regulating intestinal $\gamma \delta$ T cells. Nat Med 2016;22:516-523.

32. Yamashiro K, Tanaka R, Urabe T, Ueno Y, Yamashiro Y, Nomoto $K$, et al. Gut dysbiosis is associated with metabolism and systemic inflammation in patients with ischemic stroke. PLoS One 2017;12:e0171521.

33. Xia GH, You C, Gao XX, Zeng XL, Zhu JJ, Xu KY, et al. Stroke dysbiosis index (SDI) in gut microbiome are associated with brain injury and prognosis of stroke. Front Neuro/ 2019;10:397.

34. Stanley D, Mason $\amalg$, Mackin KE, Srikhanta YN, Lyras D, Prakash $M D$, et al. Translocation and dissemination of commensal bacteria in post-stroke infection. Nat Med 2016;22:1277-1284.

35. Crapser J, Ritzel R, Verma R, Venna VR, Liu F, Chauhan A, et al. Ischemic stroke induces gut permeability and enhances bacterial translocation leading to sepsis in aged mice. Aging (Albany NY) 2016;8:1049-1063.

36. Suda S, Aoki J, Shimoyama T, Suzuki K, Sakamoto Y, Katano $T$, et al. Stroke-associated infection independently predicts 3-month poor functional outcome and mortality. J Neurol 2018;265:370-375.

37. Prass K, Braun JS, Dirnagl U, Meisel C, Meisel A. Stroke propagates bacterial aspiration to pneumonia in a model of cerebral ischemia. Stroke 2006;37:2607-2612.

38. Ay I, Sorensen AG, Ay H. Vagus nerve stimulation reduces infarct size in rat focal cerebral ischemia: an unlikely role for 
cerebral blood flow. Brain Res 2011;1392:110-115.

39. Han Z, Shen F, He Y, Degos V, Camus M, Maze M, et al. Activation of a-7 nicotinic acetylcholine receptor reduces ischemic stroke injury through reduction of pro-inflammatory macrophages and oxidative stress. PLoS One 2014;9:e105711.

40. Engel $O$, Akyüz L, da Costa Goncalves AC, Winek K, Dames C, Thielke $M$, et al. Cholinergic pathway suppresses pulmonary innate immunity facilitating pneumonia after stroke. Stroke 2015;46:3232-3240.

41. Westendorp WF, Nederkoorn PJ, Vermeij JD, Dijkgraaf MG, van de Beek D. Post-stroke infection: a systematic review and meta-analysis. BMC Neurol 2011;11:110.

42. Dziedzic T, Slowik A, Pera J, Szczudlik A. Beta-blockers reduce the risk of early death in ischemic stroke. J Neurol Sci 2007; 252:53-56.

43. Westendorp WF, Vermeij JD, Brouwer MC, Roos YB, Nederkoorn PJ, van de Beek D, et al. Pre-stroke use of betablockers does not lower post-stroke infection rate: an exploratory analysis of the preventive antibiotics in stroke study. Cerebrovasc Dis 2016;42:506-511.

44. Kalra L, Irshad S, Hodsoll J, Simpson M, Gulliford M, Smithard $D$, et al. Prophylactic antibiotics after acute stroke for reducing pneumonia in patients with dysphagia (STROKE-INF): a prospective, cluster-randomised, open-label, masked endpoint, controlled clinical trial. Lancet 2015;386:1835-1844.

45. Westendorp WF, Vermeij JD, Zock E, Hooijenga IJ, Kruyt ND, Bosboom HJ, et al. The Preventive Antibiotics in Stroke Study (PASS): a pragmatic randomised open-label masked endpoint clinical trial. Lancet 2015;385:1519-1526.

46. Vermeij JD, Westendorp WF, Dippel DW, van de Beek D, Nederkoorn PJ. Antibiotic therapy for preventing infections in people with acute stroke. Cochrane Database Syst Rev 2018;1:CD008530.

47. Chen SC, Chen PY, Chen GC, Chuang SY, Tzeng IS, Lin SK. Portable bladder ultrasound reduces incidence of urinary tract infection and shortens hospital length of stay in patients with acute ischemic stroke. J Cardiovasc Nurs 2018; 33:551-558.

48. Ersoz M, Ulusoy $H$, Oktar MA, Akyuz M. Urinary tract infection and bacteriurua in stroke patients: frequencies, pathogen microorganisms, and risk factors. Am J Phys Med Rehabil 2007;86:734-741.

49. Titsworth WL, Hester J, Correia T, Reed R, Williams M, Guin P, et al. Reduction of catheter-associated urinary tract infections among patients in a neurological intensive care unit: a single institution's success. J Neurosurg 2012;116:911-920.

50. Johnson JR, Kuskowski MA, Wilt TJ. Systematic review: antimicrobial urinary catheters to prevent catheter-associated urinary tract infection in hospitalized patients. Ann Intern
Med 2006;144:116-126.

51. Ajmo CT Jr, Collier LA, Leonardo CC, Hall AA, Green SM, Womble TA, et al. Blockade of adrenoreceptors inhibits the splenic response to stroke. Exp Neuro/ 2009;218:47-55.

52. Harms $H$, Reimnitz $P$, Bohner $G$, Werich $T$, Klingebiel R, Meisel $C_{\text {, et }}$ al. Influence of stroke localization on autonomic activation, immunodepression, and post-stroke infection. Cerebrovasc Dis 2011;32:552-560.

53. Shi K, Wood K, Shi FD, Wang X, Liu O. Stroke-induced immunosuppression and poststroke infection. Stroke Vasc Neurol 2018;3:34-41.

54. Barugh AJ, Gray P, Shenkin SD, MacLullich AM, Mead GE. Cortisol levels and the severity and outcomes of acute stroke: a systematic review. J Neurol 2014;261:533-545.

55. Borovikova LV, Ivanova S, Zhang M, Yang H, Botchkina GI, Watkins LR, et al. Vagus nerve stimulation attenuates the systemic inflammatory response to endotoxin. Nature 2000;405: 458-462.

56. Indredavik B, Rohweder G, Naalsund E, Lydersen S. Medical complications in a comprehensive stroke unit and an early supported discharge service. Stroke 2008;39:414-420.

57. Joundi RA, Rabinstein AA, Nikneshan D, Tu JV, Fang J, Holloway $R$, et al. Cardiac arrest in acute ischemic stroke: incidence, predisposing factors, and clinical outcomes. J Stroke Cerebrovasc Dis 2016;25:1644-1652.

58. Daniele O, Caravaglios G, Fierro B, Natalè E. Stroke and cardiac arrhythmias. J Stroke Cerebrovasc Dis 2002;11:28-33.

59. Jung JM, Kim JG, Kim JB, Cho KH, Yu S, Oh K, et al. Takotsubo-like myocardial dysfunction in ischemic stroke: a hospital-based registry and systematic literature review. Stroke 2016;47:2729-2736.

60. Yoshimura S, Toyoda K, Ohara T, Nagasawa H, Ohtani N, Ku-

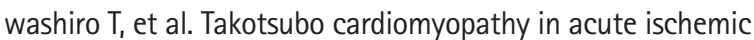
stroke. Ann Neurol 2008;64:547-554.

61. Francica JV, Bigongiari A, Mochizuki L, Scapini KB, Moraes $O A$, Mostarda $C$, et al. Cardiac autonomic dysfunction in chronic stroke women is attenuated after submaximal exercise test, as evaluated by linear and nonlinear analysis. BMC Cardiovasc Disord 2015;15:105.

62. Jia S, Xia Q, Zhang B, Wang L. Involvement of the paraventricular nucleus in the occurrence of arrhythmias in middle cerebral artery occlusion rats. J Stroke Cerebrovasc Dis 2015;24:844-851.

63. Colivicchi F, Bassi A, Santini M, Caltagirone C. Cardiac autonomic derangement and arrhythmias in right-sided stroke with insular involvement. Stroke 2004;35:2094-2098.

64. Laowattana S, Zeger SL, Lima JA, Goodman SN, Wittstein IS, Oppenheimer SM. Left insular stroke is associated with ad- 
verse cardiac outcome. Neurology 2006;66:477-483.

65. Harari D, Norton C, Lockwood L, Swift C. Treatment of constipation and fecal incontinence in stroke patients: randomized controlled trial. Stroke 2004;35:2549-2555.

66. Feng G, Xu X, Wang O, Liu Z, Li Z, Liu G. The protective effects of calcitonin gene-related peptide on gastric mucosa injury after cerebral ischemia reperfusion in rats. Regul Pept 2010;160:121-128.

67. Hsu $H L$, Lin $Y H$, Huang $Y C$, Weng $H H$, Lee $M$, Huang WY, et al. Gastrointestinal hemorrhage after acute ischemic stroke and its risk factors in Asians. Eur Neurol 2009;62:212-218.

68. Muscari A, Collini A, Fabbri E, Giovagnoli M, Napoli C, Rossi $V$, et al. Changes of liver enzymes and bilirubin during ischemic stroke: mechanisms and possible significance. BMC Neurol 2014;14:122.

69. Campos F, Sobrino T, Ramos-Cabrer P, Castellanos M, Blanco $M$, Rodríguez-Yáñez $M$, et al. High blood glutamate oxaloacetate transaminase levels are associated with good functional outcome in acute ischemic stroke. J Cereb Blood Flow Metab 2011;31:1387-1393.

70. Rink C, Gnyawali S, Stewart R, Teplitsky S, Harris H, Roy S, et al. Glutamate oxaloacetate transaminase enables anaplerotic refilling of TCA cycle intermediates in stroke-affected brain. FASEB J 2017;31:1709-1718.

71. Ottani A, Giuliani D, Mioni C, Galantucci M, Minutoli L, Bitto $A$, et al. Vagus nerve mediates the protective effects of melanocortins against cerebral and systemic damage after ischemic stroke. J Cereb Blood Flow Metab 2009;29:512-523.

72. Wang YY, Lin SY, Chuang YH, Sheu WH, Tung KC, Chen CJ. Activation of hepatic inflammatory pathways by catecholamines is associated with hepatic insulin resistance in male ischemic stroke rats. Endocrinology 2014;155:1235-1246.

73. Koch $K$, Berressem D, Konietzka J, Thinnes A, Eckert GP, Klein J. Hepatic ketogenesis induced by middle cerebral artery occlusion in mice. J Am Heart Assoc 2017;6:e005556.

74. Puchowicz MA, Zechel JL, Valerio J, Emancipator DS, Xu K, Pundik $S$, et al. Neuroprotection in diet-induced ketotic rat brain after focal ischemia. J Cereb Blood Flow Metab 2008; 28:1907-1916.

75. Hering D, Winklewski PJ. Autonomic nervous system in acute kidney injury. Clin Exp Pharmacol Physiol 2017:44:162-171.

76. Tsagalis G, Akrivos T, Alevizaki M, Manios E, Stamatellopoulos K, Laggouranis A, et al. Renal dysfunction in acute stroke: an independent predictor of long-term all combined vascular events and overall mortality. Nephrol Dial Transplant 2009; 24:194-200.

77. Arnold J, Ng KP, Sims D, Gill P, Cockwell P, Ferro C. Incidence and impact on outcomes of acute kidney injury after a stroke: a systematic review and meta-analysis. BMC Nephrol 2018;19:283.

78. Wu CL, Tsai CC, Kor CT, Tarng DC, Lian leB, Yang TH, et al. Stroke and risks of development and progression of kidney diseases and end-stage renal disease: a nationwide population-based cohort study. PLoS One 2016;11:e0158533.

79. Thomas LH, Coupe J, Cross LD, Tan AL, Watkins CL. Interventions for treating urinary incontinence after stroke in adults. Cochrane Database Syst Rev 2019;2:CD004462.

80. Vancheri F, Curcio M, Burgio A, Salvaggio S, Gruttadauria G, Lunetta $\mathrm{MC}$, et al. Impaired glucose metabolism in patients with acute stroke and no previous diagnosis of diabetes mellitus. OJM 2005;98:871-878.

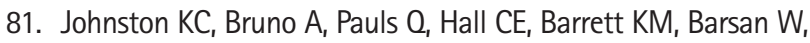
et al. Intensive vs standard treatment of hyperglycemia and functional outcome in patients with acute ischemic stroke: the SHINE randomized clinical trial. JAMA 2019;322:326-335.

82. Zhang Y, Meyer MA. Clinical analysis on alteration of thyroid hormones in the serum of patients with acute ischemic stroke. Stroke Res Treat 2010;2010:290678.

83. Cho HJ, Kim SS, Sung SM, Jung DS. Impact of thyroid autoantibodies on functional outcome in patients with acute ischemic stroke. J Stroke Cerebrovasc Dis 2014;23:1915-1920.

84. Sadana P, Coughlin L, Burke J, Woods R, Mdzinarishvili A. Anti-edema action of thyroid hormone in MCAO model of ischemic brain stroke: possible association with AQP4 modulation. J Neurol Sci 2015;354:37-45.

85. Meng $H$, Liu T, Borjigin J, Wang MM. Ischemic stroke destabilizes circadian rhythms. J Circadian Rhythms 2008;6:9.

86. Ritzenthaler T, Nighoghossian N, Berthiller J, Schott AM, Cho $\mathrm{TH}$, Derex $\mathrm{L}$, et al. Nocturnal urine melatonin and 6-sulphatoxymelatonin excretion at the acute stage of ischaemic stroke. J Pineal Res 2009;46:349-352.

87. Andrabi SS, Parvez S, Tabassum H. Melatonin and ischemic stroke: mechanistic roles and action. Adv Pharmacol Sci 2015;2015:384750.

88. Carter AR, Patel KR, Astafiev SV, Snyder AZ, Rengachary J, Strube MJ, et al. Upstream dysfunction of somatomotor functional connectivity after corticospinal damage in stroke. Neurorehabil Neural Repair 2012;26:7-19.

89. Crofts $A$, Kelly ME, Gibson CL. Imaging functional recovery following ischemic stroke: clinical and preclinical fMRI studies. J Neuroimaging 2020;30:5-14.

90. Larsen LH, Zibrandtsen IC, Wienecke T, Kjaer TW, Christensen MS, Nielsen JB, et al. Corticomuscular coherence in the acute and subacute phase after stroke. Clin Neurophysiol 2017;128:2217-2226.

91. Rosso $C$, Valabregue $R$, Attal $Y$, Vargas $P$, Gaudron $M$, Baron- 


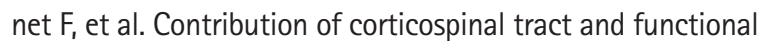
connectivity in hand motor impairment after stroke. PLoS One 2013;8:e73164.

92. Carmichael ST, Kathirvelu B, Schweppe CA, Nie EH. Molecular, cellular and functional events in axonal sprouting after stroke. Exp Neurol 2017;287(Pt 3):384-394.

93. Gao X, Zhang X, Cui L, Chen R, Zhang C, Xue J, et al. Ginsenoside $\mathrm{Rb} 1$ promotes motor functional recovery and axonal regeneration in post-stroke mice through cAMP/PKA/CREB signaling pathway. Brain Res Bull 2020;154:51-60.

94. Li F, Liu WC, Wang $Q$, Sun Y, Wang H, Jin X. NG2-glia cell proliferation and differentiation by glial growth factor 2 (GGF2), a strategy to promote functional recovery after ischemic stroke. Biochem Pharmacol 2020;171:113720.

95. Yuan L, Sun S, Pan X, Zheng L, Li Y, Yang J, et al. Pseudoginsenoside-F11 improves long-term neurological function and promotes neurogenesis after transient cerebral ischemia in mice. Neurochem Int 2020;133:104586.

96. Wilkins KB, Owen M, Ingo C, Carmona C, Dewald JPA, Yao J. Neural plasticity in moderate to severe chronic stroke following a device-assisted task-specific arm/hand intervention. Front Neurol 2017;8:284.

97. Kim SY, Allred RP, Adkins DL, Tennant KA, Donlan NA, Kleim $J A$, et al. Experience with the "good" limb induces aberrant synaptic plasticity in the perilesion cortex after stroke. $J$ Neurosci 2015;35:8604-8610.

98. Fregni F, Pascual-Leone A. Hand motor recovery after stroke: tuning the orchestra to improve hand motor function. Cogn Behav Neurol 2006;19:21-33.

99. Zaaimi B, Edgley SA, Soteropoulos DS, Baker SN. Changes in descending motor pathway connectivity after corticospinal tract lesion in macaque monkey. Brain 2012;135(Pt 7):22772289.

100. Pongmoragot J, Rabinstein AA, Nilanont $Y$, Swartz RH, Zhou $L$, Saposnik G, et al. Pulmonary embolism in ischemic stroke: clinical presentation, risk factors, and outcome. J Am Heart Assoc 2013;2:e000372.

101. Rinde LB, Småbrekke B, Mathiesen EB, Løchen ML, Njølstad I, Hald EM, et al. Ischemic stroke and risk of venous thromboembolism in the general population: the Tromsø study. J Am Heart Assoc 2016;5:e004311.

102. Dennis M, Sandercock P, Graham C, Forbes J; CLOTS (Clots in Legs Or sTockings after Stroke) Trials Collaboration, Smith J. The Clots in Legs Or sTockings after Stroke (CLOTS) 3 trial: a randomised controlled trial to determine whether or not intermittent pneumatic compression reduces the risk of poststroke deep vein thrombosis and to estimate its cost-effec- tiveness. Health Technol Assess 2015;19:1-90.

103. Kanis J, Oden A, Johnell 0 . Acute and long-term increase in fracture risk after hospitalization for stroke. Stroke 2001; 32:702-706.

104. Vignaux G, Ndong JD, Perrien DS, Elefteriou F. Inner ear vestibular signals regulate bone remodeling via the sympathetic nervous system. J Bone Miner Res 2015;30:1103-1111.

105. Borschmann KN, Rewell SS, Iuliano S, Ghasem-Zadeh A, Davey $\mathrm{RA}, \mathrm{Ho} H$, et al. Reduced bone formation markers, and altered trabecular and cortical bone mineral densities of non-paretic femurs observed in rats with ischemic stroke: a randomized controlled pilot study. PLoS One 2017;12:e0172889.

106. Hafer-Macko CE, Ryan AS, Ivey FM, Macko RF. Skeletal muscle changes after hemiparetic stroke and potential beneficial effects of exercise intervention strategies. J Rehabil Res Dev 2008;45:261-272.

107. Springer J, Schust S, Peske $K$, Tschirner A, Rex A, Engel O, et al. Catabolic signaling and muscle wasting after acute ischemic stroke in mice: indication for a stroke-specific sarcopenia. Stroke 2014;45:3675-3683.

108. Desgeorges MM, Devillard X, Toutain J, Castells J, Divoux D, Arnould DF, et al. Pharmacological inhibition of myostatin improves skeletal muscle mass and function in a mouse model of stroke. Sci Rep 2017;7:14000.

109. Ryan AS, Ivey FM, Prior S, Li G, Hafer-Macko C. Skeletal muscle hypertrophy and muscle myostatin reduction after resistive training in stroke survivors. Stroke 2011;42:416-420.

110. Kidwell CS, Liebeskind DS, Starkman S, Saver JL. Trends in acute ischemic stroke trials through the 20th century. Stroke $2001 ; 32: 1349-1359$.

111. Morelli VM, Sejrup JK, Småbrekke B, Rinde LB, Grimnes G, Isaksen $T$, et al. The role of stroke as a trigger for incident venous thromboembolism: results from a population-based case-crossover study. TH Open 2019;3:e50-e57.

112. Hachinski VC, Oppenheimer SM, Wilson JX, Guiraudon C, Cechetto DF. Asymmetry of sympathetic consequences of experimental stroke. Arch Neurol 1992;49:697-702.

113. Dziedzic T, Slowik A, Szczudlik A. Urine albumin excretion in acute ischaemic stroke is related to serum interleukin-6. Clin Chem Lab Med 2004;42:182-185.

114. Shrestha P, Thapa S, Shrestha S, Lohani S, Bk S, MacCormac 0 , et al. Renal impairment in stroke patients: a comparison between the haemorrhagic and ischemic variants. Version 2. F1000Res 2017;6:1531.

115. Pang MY, Eng JJ. Muscle strength is a determinant of bone mineral content in the hemiparetic upper extremity: implications for stroke rehabilitation. Bone 2005;37:103-111. 
Supplementary Table 1. Literature summary: systemic pathophysiology of ischemic stroke

\begin{tabular}{|c|c|}
\hline Study & Summary \\
\hline \multicolumn{2}{|l|}{ Immune system: immunosuppression } \\
\hline \multicolumn{2}{|l|}{ Pre-clinical } \\
\hline Offner et al. (2006a) ${ }^{1}$ & Ischemic stroke activates the peripheral immune system with acute alterations in the spleen. \\
\hline Offner et al. (2006b) ${ }^{2}$ & Immunosuppression yields splenic atrophy, lower T-cell response, increased CD4+FoxP3+Treg cells. \\
\hline Gu et al. $(2012)^{3}$ & Stroke affects T-cell populations and prompts an inflammatory shift from Th1 to Th2 response. \\
\hline Gu et al. $(2013)^{4}$ & T-cell dysfunction after stroke is a main contributor to immune cell reduction in blood and spleen. \\
\hline Braun et al. $(2007)^{5}$ & Q-VD-OPH prevented brain damage, splenic/thymic apoptosis, infection; improved survival. \\
\hline Wong et al. $(2011)^{6 *}$ & Hepatic iNKT cell behavior is altered via noradrenergic signaling; contributes to immunosuppression. \\
\hline Kim et al. $(2018)^{7}$ & HMBG1 release causes inflammation in the brain and periphery and is associated with infection. \\
\hline Walker et al. (2010) ${ }^{8}$ & Other CNS injuries such as TBI reduce splenic volume and present some benefit to splenectomy. \\
\hline Ajmo et al. $(2008)^{9}$ & Splenectomy 2 weeks pre-stroke decreased activated microglia/peripheral immune cells and infarct volume. \\
\hline Dotson et al. $(2015)^{10}$ & Splenectomy 2 weeks pre-stroke decreased infarct size and inflammation in male mice but not females. \\
\hline Kim et al. (2014)11 & Pre-stroke splenectomy reduced monocyte/macrophage infiltration, not infarct growth/edema. \\
\hline Zierath et al. $(2017)^{12}$ & Pre-stroke splenectomy had no effect on infarct volume, immune response to brain antigen, outcomes. \\
\hline Belinga et al. $(2016)^{13}$ & Post-stroke splenectomy was neuroprotective via reduced TLR4/NF-KB expression, inflammation. \\
\hline Kharrazian $(2015)^{14}$ & The gut microbiome is disrupted after other neurological injuries such as TBI. \\
\hline Kigerl et al. (2018) $)^{15}$ & Other CNS injuries such as $\mathrm{SCl}$ cause dysbiosis, intestinal permeability, bacterial translocation. \\
\hline Singh et al. (2016) $)^{16 *}$ & Dysbiosis is associated with immune dysfunction/poor outcomes. \\
\hline Stanley et al. (2018) ${ }^{17}$ & Stroke alters gut microbiome within 24 hours. \\
\hline Winek et al. (2016) ${ }^{18}$ & Microbiota-depletion with antibiotics until 3 days pre-stroke caused colitis/decreased survival. \\
\hline Tascilar et al. $(2010)^{19}$ & pMCAO caused intestinal mucosal damage/bacterial translocation at PSD1-3. \\
\hline Benakis et al. $(2016)^{20}$ & Gut dysbiosis directly affects intestinal T-cells and exacerbates stroke evolution. \\
\hline Crapser et al. $(2016)^{21}$ & Gut permeability/bacterial translocation contribute to infection after stroke induction. \\
\hline Oyama et al. $\left(2018^{22}\right.$ & Gut permeability/bacterial translocation were not seen 24 to 72 hours post-tMCAO. \\
\hline \multicolumn{2}{|l|}{ Clinical } \\
\hline Chamorro et al. $(2012)^{23 *,+}$ & Brain-immune interaction aids immunosuppression; increases infection/morbidity/mortality. \\
\hline Liu et al. $(2017)^{24+}$ & Immunosuppression in the brain and periphery is controlled by separate and distinct mechanisms. \\
\hline Johnston et al. $(1998)^{25 *}$ & Pneumonia, UTI, congestive heart failure, and others contribute to mortality/negative outcomes. \\
\hline Chiu et al. $(2016)^{26}$ & Splenic atrophy correlates with increased blood lymphocytes/decreased blood neutrophils. \\
\hline Vogelgesang et al. $(2008)^{27 *}$ & Slow CD4+ T cell count recovery may identify patients at risk of infection. \\
\hline Mocco et al. $(2006)^{28}$ & $\begin{array}{l}\text { Stroke activates the complement system, as demonstrated in peripheral blood levels of complement factor } \\
\text { 3a (acute increase), 5a (delayed increase), and sC5b-9 (acute decrease). }\end{array}$ \\
\hline Planas et al. $(2012)^{29}$ & Lymph node $\mathrm{CD} 68+\mathrm{MHCll}+$ macrophages near activated T-cells react to neuronal antigens. \\
\hline Yang et al. $(2011)^{30+}$ & Brain-derived HMGB1 prompts inflammatory response, ischemia-reperfusion injury via TLR4. \\
\hline Liesz et al. $(2015)^{31 *,+}$ & DAMPs/HMBG1-RAGE contribute to monocyte exhaustion, lymphopenia, immune suppression. \\
\hline Harms et al. $(2008)^{32}$ & PSD1 monocytic HLA-DR level is an independent predictor of infection. \\
\hline Hug et al. (2009) ${ }^{33 *}$ & Infarct volume predicted SAP; associated with decreased HLA-DR, lymphocytopenia, monocyte dysfunction. \\
\hline Hernandez-Jimenez et al. $(2017)^{34}$ & Impaired monocyte function/low HLA-DR correlate with circulating mtDNA; identifies infection risk. \\
\hline Hoffmann et al. $(2017)^{35 *}$ & Immunodepression (reduced monocytic HLA-DR) and dysphagia are independent, screenable predictors of SAP. \\
\hline van de Beek et al. (2009) $)^{36 *}$ & Meta-analysis of post-stroke infection confirmed no benefit of prophylactic antibiotics over standard treatment. \\
\hline
\end{tabular}


Supplementary Table 1. Continued

\begin{tabular}{|c|c|}
\hline Study & Summary \\
\hline Badve et al. $(2018)^{37 *}$ & Evidence is insufficient to recommend routine administration of post-stroke antibiotics for infection control. \\
\hline Yin et al. $(2015)^{38}$ & Stroke causes gut dysbiosis and low blood TMAO levels. \\
\hline Stanley et al. $(2016)^{39+}$ & Gut permeability promotes bacterial translocation and infection. \\
\hline Yamashiro et al. $(2017)^{40,41}$ & Gut dysbiosis is associated with changes to host metabolism, inflammation. \\
\hline \multicolumn{2}{|c|}{$\begin{array}{l}\text { Autonomic/neuroendocrine systems: sympathet- } \\
\text { ic, parasympathetic, and HPA axis dysfunction }\end{array}$} \\
\hline \multicolumn{2}{|l|}{ Pre-clinical } \\
\hline Prass et al. $(2003)^{42}$ & Catecholamines mediate immunodepression, infection, splenic atrophy, lymphocyte apoptosis. \\
\hline Ajmo et al. (2009) ${ }^{43}$ & Splenic response is regulated by catecholamines, $\alpha$ - and $\beta$-adrenergic receptors. \\
\hline Yan et al. (2014) $)^{44}$ & $\begin{array}{l}\text { Sympathetic overactivation after stroke suppresses the immune system and reduces splenic volume; } \\
\text { reversible with sympathetic block. }\end{array}$ \\
\hline Mracsko et al. (2014) $)^{45}$ & Immune compromise is mediated by SNS and HPA axis dysfunction. \\
\hline Ay et al. $(2011)^{46}$ & Vagal stimulation confirmed role of a7-nAChR in reducing cerebral ischemia after stroke. \\
\hline Han et al. (2014) $)^{47}$ & a7-nAChR activation decreases cerebral inflammation following experimental stroke. \\
\hline Engel et al. (2015) ${ }^{48}$ & $\begin{array}{l}\text { The parasympathetic anti-inflammatory cholinergic pathway is activated after stroke and contributed to } \\
\text { pneumonia development; prevented with vagotomy or a7-nAChR deficiency. }\end{array}$ \\
\hline \multicolumn{2}{|l|}{ Clinical } \\
\hline Chamorro et al. $(2007)^{49}$ & Stroke-induced circulating catecholamines were associated with infection and 3 months mortality. \\
\hline McCulloch et al. $(2017)^{50+}$ & ß2-Adrenergic receptors mediate marginal zone B-cell/plasma lgM loss, high bacterial load, infection. \\
\hline Dziedzic et al. $(2007)^{51}$ & $\beta$-Blockers reduced mortality independent of other risk factors. \\
\hline Sykora et al. $(2015)^{52 *}$ & On-stroke $\beta$-blockers decreased pneumonia/mortality; no effect on function. \\
\hline De Raedt et al. $(2011)^{53}$ & Pre-stroke $\beta$-blocker use did not impact stroke severity/3 months outcome. \\
\hline Maier et al. (2018) ${ }^{54}$ & $\begin{array}{l}\beta \text {-Blocker therapy had no reduction effect on post-stroke infections and was indicated as a possible } \\
\text { contributor to UTI development. }\end{array}$ \\
\hline Westendorp et al. (2016) $)^{55}$ & Pre-stroke use of $\beta$-blockers was associated with higher infection incidence and SAP. \\
\hline Starr et al. $(2017)^{56}$ & Non-selective $\beta$-blockers were associated with infection; no effect on disability/mortality. \\
\hline Harms et al. $(2011)^{57 *}$ & Anterior MCA lesion/high urine NE associated with low monocyte HLA-DR, predicted infection. \\
\hline Haeusler et al. $(2008)^{58}$ & $\begin{array}{l}\text { Immunosuppression presents with decreased lymphocytes and monocyte/Th1 function. Plasma cortisol was } \\
\text { elevated in patients who later developed infection. }\end{array}$ \\
\hline Barugh et al. $(2014)^{59}$ & Stroke-increased cortisol is associated with dependency, mortality, lymphopenia, stroke severity. \\
\hline \multicolumn{2}{|c|}{$\begin{array}{l}\text { Respiratory system: stroke-associated pneu- } \\
\text { monia }\end{array}$} \\
\hline \multicolumn{2}{|l|}{ Pre-clinical } \\
\hline Prass et al. $(2006)^{60}$ & Immunodeficiency facilitates spontaneous bacteremia/pneumonia via sympathetic activity. \\
\hline Suda et al. $(2018)^{61}$ & Infection during hospitalization predicts worse functional outcome/death at 3 months. \\
\hline \multicolumn{2}{|l|}{ Clinical } \\
\hline Walter et al. $(2007)^{62}$ & Dysphagia, infection on admission, and NIHSS score predict SAP in NICU. \\
\hline Lakshminarayan et al. (2010) $)^{63}$ & Dysphagia screening predicts pneumonia, but broader selection criteria are warranted. \\
\hline Kalra et al. (2015) ${ }^{64}$ & Clinical trial found prophylactic antibiotics for SAP failed to improve outcomes/mortality. \\
\hline Xi et al. $(2017)^{65}$ & Antibiotic use for SAP had no impact on functional outcomes or mortality. \\
\hline \multicolumn{2}{|c|}{$\begin{array}{l}\text { Respiratory system: venous thromboembo- } \\
\text { lisms-DVT/PE }\end{array}$} \\
\hline Clinical & \\
\hline
\end{tabular}


Supplementary Table 1. Continued

\begin{tabular}{|c|c|}
\hline Study & Summary \\
\hline Kelly et al. (2004) $)^{66}$ & $\begin{array}{l}\text { Ischemic stroke patients are at risk for VTE; half of DVT and PE cases identified via magnetic resonance direct } \\
\text { thrombus imaging had been overlooked by the attending team. }\end{array}$ \\
\hline Pilato et al. (2013) ${ }^{67}$ & Case report stressed clinical risks/concerns of post-stroke, post-thrombolysis PE. \\
\hline Pongmoragot et al. $(2013)^{68}$ & PE is associated with in-hospital complications, disability, poor outcome, fatality within 1 year. \\
\hline Bembenek et al. $(2012)^{69}$ & DVT incidence is $9 \%$ within 1 week, predicted by high CRP/pre-stroke disability. \\
\hline Douds et al. (2014) ${ }^{70}$ & VTE incidence was 3\% despite VTE prophylaxis. \\
\hline Rinde et al. (2016) ${ }^{71}$ & VTE risk after stroke increases 3-fold within 3 months. \\
\hline Sandercock et al. $(2015)^{72}$ & Routine anti-coagulants are not recommended for DVT/PE prevention due to hemorrhage risk. \\
\hline CLOTS Trials Collaboration (2013) ${ }^{73}$ & IPC devices are effective at reducing DVT risk. \\
\hline Dennis et al. $(2015)^{74}$ & Anticoagulants decrease VTEs, increase bleed risk. IPCs reduced DVTs in immobile patients. \\
\hline Morelli et al. (2019) $)^{75}$ & $\begin{array}{l}\text { Post-stroke infection may contribute to VTE development through coagulation system activation and } \\
\text { resulting immobilization. }\end{array}$ \\
\hline \multicolumn{2}{|l|}{ Urinary system: urinary tract infection } \\
\hline \multicolumn{2}{|l|}{ Clinical } \\
\hline Ersoz et al. $(2007)^{76}$ & Post-stroke UTI affects patients both with (50\%) and without (24\%) indwelling catheters. \\
\hline Indredavik et al. (2008) $)^{77 *}$ & UTI is a common complication at 1 week and 3 months. \\
\hline Stott et al. (2009) ${ }^{78}$ & UTIs are associated with catheter use, disability, death. \\
\hline Ifejika-Jones et al. $(2013)^{79}$ & In-hospital UTI predicts discharge setting dependency. \\
\hline Huang et al. (2004) $)^{80}$ & Prompting removal of urinary catheters decreased incidence of UTI in ICU patients. \\
\hline Topal et al. $(2005)^{81}$ & Assessment prompts and bladder scans reduced catheter use and incidence of post-stroke UTI. \\
\hline Titsworth et al. $(2012)^{82}$ & Programs emphasizing sterility, less catheter use, and early removal decreased use and UTI rates. \\
\hline Chen et al. $(2018)^{83}$ & Portable bladder ultrasound (residual post-void volume) reduced UTIs even with catheterization. \\
\hline Muramatsu et al. $(2018)^{84}$ & Antimicrobial catheter use did not reduce catheter-associated UTIs. \\
\hline \multicolumn{2}{|l|}{ Urinary system: renal dysfunction } \\
\hline \multicolumn{2}{|l|}{ Pre-clinical } \\
\hline Hachinski et al. (1992) $)^{85}$ & Renal nerve sympathetic activity/plasma NE present differently in left vs. right MCAO. \\
\hline \multicolumn{2}{|l|}{ Clinical } \\
\hline Dziedzic et al. $(2004)^{86}$ & Urine albumin and serum IL-6 are elevated after stroke. \\
\hline Thomas et al. (2019) ${ }^{87}$ & $\begin{array}{l}\text { Urinary incontinence affects half of stroke patients with 15\% still incontinent at } 1 \text { year; evidence to direct } \\
\text { continence interventions is insufficient. }\end{array}$ \\
\hline Pettersen et al. $(2006)^{88}$ & Urinary incontinence with impaired awareness after stroke predicted mortality and 3 months outcome. \\
\hline Lee et al. $(2016)^{89}$ & Albuminuria after stroke is associated with additional adverse events and mortality. \\
\hline Tsagalis et al. $(2009)^{90}$ & Low eGFR predicts cardiovascular complications/mortality within 10 years. \\
\hline Shrestha et al. $(2017)^{91}$ & Stroke reduces eGFR, causes renal impairment. \\
\hline Khatri et al. $(2014)^{92}$ & AKI is common and is associated with in-hospital mortality. \\
\hline Nadkarni et al. (2015) ${ }^{93}$ & AKI with dialysis is linked to higher discharge dependency/death. \\
\hline Zorrilla-Vaca et al. (2018) ${ }^{94}$ & AKI is associated with mortality; kidney function should be tested acutely. \\
\hline Arnold et al. (2018) ${ }^{95}$ & Inflammation and sympathetic output contribute to AKI within 48 hours of stroke. \\
\hline Wu et al. (2016) $)^{96}$ & Stroke increases risk of renal dysfunction, CKD, ESRD. \\
\hline \multicolumn{2}{|l|}{ Cardiovascular system: cardiac dysfunction } \\
\hline Pre-clinical & \\
\hline
\end{tabular}


Supplementary Table 1. Continued

\begin{tabular}{|c|c|}
\hline Study & Summary \\
\hline Jia et al. $(2015)^{97}$ & MCAO causes cardiac arrhythmias via glutamate-mediated PVN activation. \\
\hline Bieber et al. (2017) ${ }^{98}$ & Sympathetic signaling causes systolic dysfunction. \\
\hline \multicolumn{2}{|l|}{ Clinical } \\
\hline Daniele et al. (2002) $)^{99}$ & Stroke causes new-onset ECG abnormalities, commonly arrhythmias. \\
\hline Di Pasquale et al. (1988) $)^{100}$ & $\begin{array}{l}\text { Exercise testing revealed silent myocardial ischemia in stroke patients without symptoms of ischemic heart } \\
\text { disease. }\end{array}$ \\
\hline Adams et al. $(2003)^{101}$ & Some stroke patients may have asymptomatic coronary artery disease. \\
\hline Ay et al. (2006) & Cardiac troponin T is elevated without apparent injury. \\
\hline Touze et al. $(2005)^{103}$ & Risk of $\mathrm{Ml}$ and vascular death is high after ischemic stroke; screening efforts need improved. \\
\hline Joundi et al. (2016) $)^{104}$ & Cardiac arrest correlates with severe comorbidities/disability/30-day mortality. \\
\hline Prosser et al. (2007) ${ }^{105}$ & Serious adverse events are common during week 2 and predictable. \\
\hline Yoshimura et al. (2008) $)^{106}$ & TC is common in women with insular/vertebrobasilar infarcts. \\
\hline Jung et al. (2016) ${ }^{107}$ & Post-stroke TC is associated with insular infarcts, poor outcomes, inflammation, and mortality. \\
\hline Milionis et al. (2013) ${ }^{108}$ & Low left ventricular EF is associated with disability/comorbidity/death within 1 year. \\
\hline Colivicchi et al. (2004) $)^{109}$ & Right insular lesions are associated with cardiac dysfunction/arrhythmias. \\
\hline Laowattana et al. (2006) ${ }^{110}$ & Left insular lesions predicted MI/cardiac death; right had no association. \\
\hline Korpelainen et al. (1996) ${ }^{111}$ & Medulla lesions cause abnormal HRV. \\
\hline Francica et al. (2015) ${ }^{112}$ & Submaximal exercise improved HRV and cardiac vagal modulation. \\
\hline Tahsili-Fahadan et al. (2017) ${ }^{113}$ & Stroke induces abnormal ECG, arrhythmias, elevated enzymes. \\
\hline \multicolumn{2}{|c|}{$\begin{array}{l}\text { Digestive system: gastrointestinal complica- } \\
\text { tions }\end{array}$} \\
\hline \multicolumn{2}{|l|}{ Pre-clinical } \\
\hline Xu et al. $(2012)^{114}$ & MCAO increased intestinal mucosal damage/ghrelin, decreased motility. \\
\hline Feng et al. $(2010)^{115}$ & CGRP at reperfusion attenuates gastric mucosal damage. \\
\hline \multicolumn{2}{|l|}{ Clinical } \\
\hline Hsu et al. (2009) ${ }^{116}$ & GI hemorrhage increased proportionate to number of risk factors. \\
\hline Chen et al. (2011) $)^{117}$ & Risks for upper GI bleeds include impaired consciousness, longer stay, anticoagulant use. \\
\hline Ogata et al. (2014) 118 & GI bleeds are rare and linked to mortality/poor outcome. \\
\hline Li et al. $(2017)^{119}$ & Nearly half of patients suffer from bowel complications. \\
\hline Harari et al. $(2003)^{120}$ & New-onset fecal incontinence affects 30\% of patients, lasting up to 3 years. \\
\hline Schaller et al. (2006) ${ }^{121}$ & GI complications contribute to poor nutrition status linked with worse outcomes. \\
\hline Yi et al. $(2011)^{122}$ & Constipation presented with impaired swallowing/colon motility. \\
\hline
\end{tabular}

Digestive system: hepatic dysfunction

Pre-clinical

Ottani et al. (2009) ${ }^{123}$

Stroke activates inflammatory/apoptotic pathways in the liver.

Puchowicz et al. (2008) 124

Diet-induced ketosis proved neuroprotective in rat brain after MCAO.

Koch et al. (2017) ${ }^{125}$

Stroke induced hepatic ketogenesis and production of neuroprotective hepatic $\beta \mathrm{OHB}$, mediated through noradrenergic innervation.

Wang et al. (2014) $)^{126}$

Catecholamine levels compromise hepatic insulin signaling, increase expression of gluconeogenic genes, and increase endoplasmic reticulum stress in the liver after stroke.

Clinical 
Supplementary Table 1. Continued

\begin{tabular}{|c|c|}
\hline Study & Summary \\
\hline Pineda et al. (2008) $)^{127}$ & Serum direct bilirubin is increased after stroke and associated with higher stroke severity. \\
\hline Luo et al. (2013) $)^{128}$ & Stroke elevated serum direct bilirubin and total bilirubin, correlating with stroke severity. \\
\hline Muscari et al. (2014) & Stroke alters unconjugated bilirubin/liver enzyme levels. \\
\hline \multicolumn{2}{|c|}{ Endocrine system: insulin and hyperglycemia } \\
\hline \multicolumn{2}{|l|}{ Pre-clinical } \\
\hline Zhu et al. (2004) & Optimal blood glucose must be maintained to avoid both hyper- and hypoglycemia. \\
\hline \multicolumn{2}{|l|}{ Clinical } \\
\hline Szczudlik et al. (2001) $)^{131}$ & Post-stroke transient hyperglycemia is common and increases 30 -day mortality. \\
\hline Baird et al. $(2003)^{132}$ & Persistent hyperglycemia was associated with poor function and infarct expansion. \\
\hline Vancheri et al. (2005) $)^{133}$ & Post-load hyperglycemia at discharge predicts new-onset diabetes after 3 months. \\
\hline Ntaios et al. $(2010)^{134}$ & Both hyper- and hypoglycemia are dangerous and affect outcome. \\
\hline Gray et al. (2004) $)^{135}$ & GKI infusion corrected hyperglycemia with low risk of hypoglycemia. \\
\hline Bruno et al. $(2008)^{136}$ & Aggressive hyperglycemia correction was well-tolerated and superior to routine care. \\
\hline Bruno et al. (2014) $)^{137}$ & More evidence is needed to argue continuous insulin infusion vs. standard subcutaneous insulin. \\
\hline Johnston et al. (2019) ${ }^{138}$ & The SHINE clinical trial found no therapeutic benefit of aggressive treatment of hyperglycemia. \\
\hline \multicolumn{2}{|c|}{$\begin{array}{l}\text { Endocrine system: low T3 and positive thyroid } \\
\text { autoantibodies }\end{array}$} \\
\hline \multicolumn{2}{|l|}{ Pre-clinical } \\
\hline Sadana et al. $(2015)^{139}$ & Neuroprotective T3 decreases edema via AQP4 suppression. \\
\hline \multicolumn{2}{|l|}{ Clinical } \\
\hline Zhang et al. (2010) $)^{140}$ & Low T3 is associated with high severity scores and worse outcome. \\
\hline Cho et al. $(2014)^{141}$ & Positive thyroid autoantibodies correlated with unfavorable outcomes. \\
\hline \multicolumn{2}{|c|}{$\begin{array}{l}\text { Endocrine system: melatonin and circadian } \\
\text { dysfunction }\end{array}$} \\
\hline \multicolumn{2}{|c|}{ Pre-clinical } \\
\hline Meng et al. (2008) ${ }^{142}$ & Stroke shifts timing of melatonin secretion. \\
\hline Bhattacharya et al. (2014) ${ }^{143}$ & Neuroprotective melatonin reduced infarct size, deficits, edema, and apoptosis. \\
\hline Kilic et al. (2004) $)^{144}$ & Melatonin protects against neuronal injury through inhibition of caspase-3. \\
\hline Kilic et al. (2005) $)^{145}$ & Acute neuroprotection from melatonin involves phosphatidyl inositol-3 kinase/Akt signaling. \\
\hline Manev et al. (1996) $)^{146}$ & Melatonin-deficient rats exhibit greater neurodegeneration. \\
\hline \multicolumn{2}{|l|}{ Clinical } \\
\hline Ritzenthaler et al. (2009) $)^{147}$ & Stroke decreases nocturnal urinary melatonin excretion. \\
\hline Vinogradov et al. (2015) ${ }^{148}$ & Melatonin assisted recovery from sleep initiation disturbance insomnia. \\
\hline \multicolumn{2}{|c|}{$\begin{array}{l}\text { Musculoskeletal system: bone loss and remod- } \\
\text { eling disorder }\end{array}$} \\
\hline \multicolumn{2}{|l|}{ Pre-clinical } \\
\hline Borschmann et al. $(2017)^{149}$ & Serum PINP was significantly reduced at PSD28. \\
\hline Vignaux et al. (2015) & Bone metabolism/skeletal homeostasis disruption is attributed to sympathetic hyperactivation. \\
\hline \multicolumn{2}{|l|}{ Clinical } \\
\hline Kanis et al. $(2001)^{151}$ & Fracture risk increases 7-fold within first year of hospitalization. \\
\hline
\end{tabular}




\begin{tabular}{|c|c|}
\hline Study & Summary \\
\hline Pang et al. (2005) ${ }^{152}$ & The paretic arm presents with lower BMD/BMC/lean mass and higher fat mass. \\
\hline Pang et al. (2007) $)^{153}$ & Upper extremity impairment measures are determinants of bone demineralization. \\
\hline Kapral et al. (2017) ${ }^{154}$ & Low-trauma fracture risk increases after stroke, supporting need for BMD screening. \\
\hline Borschmann et al. (2018) $)^{155}$ & Motor control, standing/walking recovery at 6 months inversely correlated with bone loss. \\
\hline \multicolumn{2}{|c|}{$\begin{array}{l}\text { Musculoskeletal system: skeletal muscle } \\
\text { pathophysiology }\end{array}$} \\
\hline \multicolumn{2}{|l|}{ Pre-clinical } \\
\hline Desgeorges et al. (2015) $)^{156}$ & Akt/mTOR repression and increased ubiquitin-proteasome activity contribute to atrophy. \\
\hline Springer et al. (2014) $)^{157}$ & Catabolic/proteasome activity were not prevented by autonomic/immune intervention. \\
\hline Sen et al. $(2017)^{158}$ & Stroke disrupts inflammatory and regenerative signaling in muscle. \\
\hline Desgeorges et al. (2017) $)^{159}$ & Anti-myostatin treatment reduced muscle loss and improved function. \\
\hline \multicolumn{2}{|l|}{ Clinical } \\
\hline Jorgensen et al. (2001) $)^{160}$ & Loss of lean muscle mass and BMC are common during the first year. \\
\hline Benecke et al. $(1983)^{161}$ & Upper limb denervation occurs at 2 to 3 weeks, after which denervation decreases. \\
\hline De Deyne et al. (2004) $)^{162}$ & Myofiber phenotype changes contribute to functional disability. \\
\hline Ryan et al. (2011) $)^{163}$ & Resistance training repressed myostatin and induced hypertrophy. \\
\hline Scherbakov et al. (2013) ${ }^{164}$ & Muscle pathologies present but are not addressed in rehabilitation guidelines. \\
\hline \multicolumn{2}{|c|}{ Referenced guidelines and statistic reports } \\
\hline Benjamin et al. (2019) $)^{165 *}$ & Heart disease and stroke statistics-2019 update: a report from the American Heart Association \\
\hline Collaborators GBDN (2019) ${ }^{166 *}$ & $\begin{array}{l}\text { Global, regional, and national burden of neurological disorders, 1990-2016: a systematic analysis for the } \\
\text { global burden of disease study } 2016\end{array}$ \\
\hline Collaborators GBDS (2019) ${ }^{167 *}$ & $\begin{array}{l}\text { Global, regional, and national burden of stroke, 1990-2016: a systematic analysis for the global burden of } \\
\text { disease study } 2016\end{array}$ \\
\hline Powers et al. (2018) ${ }^{168 *}$ & $\begin{array}{l}2018 \text { Guidelines for the early management of patients with acute ischemic stroke: a guideline for healthcare } \\
\text { professionals from the American Heart Association/American Stroke Association }\end{array}$ \\
\hline Pierot et al. (2018) ${ }^{169}$ & Standards of practice in acute ischemic stroke intervention: international recommendations \\
\hline Sacks et al. (2018) $)^{170}$ & $\begin{array}{l}\text { Multisociety consensus quality improvement revised consensus statement for endovascular therapy of acute } \\
\text { ischemic stroke: from the American Association of Neurological Surgeons (AANS), American Society of } \\
\text { Neuroradiology (ASNR), Cardiovascular and Interventional Radiology Society of Europe (CIRSE), Canadian } \\
\text { Interventional Radiology Association (CIRA), Congress of Neurological Surgeons (CNS), European Society of } \\
\text { Minimally Invasive Neurological Therapy (ESMINT), European Society of Neuroradiology (ESNR), European Stroke } \\
\text { Organization (ESO), Society for Cardiovascular Angiography and Interventions (SCAI), Society of Interventional } \\
\text { Radiology (SIR), Society of Neurointerventional Surgery (SNIS), and World Stroke Organization (WSO) }\end{array}$ \\
\hline Johnson et al. (2016) ${ }^{171}$ & Stroke: a global response is needed. World Health Organization Bulletin \\
\hline Winstein et al. (2016) $)^{172 *}$ & $\begin{array}{l}\text { Guidelines for adult stroke rehabilitation and recovery: a guideline for healthcare professionals from the } \\
\text { American Heart Association/American Stroke Association }\end{array}$ \\
\hline Platz (2019) $)^{173 *}$ & Evidence-based guidelines and clinical pathways in stroke rehabilitation-an international perspective \\
\hline
\end{tabular}

CD4, cluster of differentiation 4; FoxP3, forkhead box protein P3; Treg, regulatory T-cell; Th, T-helper; Q-VD-OPH, quinolyl-valyl-0-methylaspartyl-[-2,6-difluorophenoxy]-methyl ketone; iNKT, invariant natural killer T (cell); HMBG1, high-mobility group box 1; CNS, central nervous system; TBI, traumatic brain injury; TLR, toll-like receptor; NF-KB, Nuclear factor $\mathrm{KB}$; SCl, spinal cord injury; PSD, post-stroke day; pMCAO, permanent MCA occlusion; tMCAO, transient MCA0; UTI, urinary tract infection; MHC, major histocompatibility complex; DAMP, danger-associated molecular pattern; RAGE, receptor for advanced glycation end product; HLA-DR, human leukocyte antigen D related; SAP, stroke-associated pneumonia; mtDNA, mitochondrial DNA; TMAO, trimethylamine N-oxide; HPA, hypothalamic-pituitary adrenal; SNS, sympathetic nervous system; nAChR, nicotinic acetylcholine receptor; lgM, immunoglobulin M; MCA, middle cerebral artery; NE, norepinephrine; NIHSS, National Institutes of Health Stroke Scale; NICU, neurological intensive care unit; DVT, deep vein thrombosis; PE, pulmonary embolism; VTE, venous thromboembolism; CRP, C-reactive protein; IPC, intermittent pneumatic compression; ICU, intensive care unit; IL-6, interleukin 6; eGFR, estimated glomerular filtration rate; AKI, acute kidney injury; CKD, chronic kidney disease; ESRD, end-stage renal disease; PVN, paraventricular nucleus; ECG, electrocardiography; MI, myocardial infarction; TTC, Takotsubo cardiomyopathy; EF, ejection fraction; HRV, heart rate variability; CGRP, calcitonin gene-related peptide; Gl, gastrointestinal; $\beta O H B, \beta$-hydroxybutyrate; GKI, glucose/potassium/insulin; SHINE, Stroke Hyperglycemia Insulin Network Effort; T3, triiodothyronine; AQP4, aquaporin-4; PINP, $\mathrm{N}$-terminal propeptide of type 1 procollagen; $\mathrm{BMD}$, bone mineral density; $\mathrm{BMC}$, bone mineral content; $\mathrm{mTOR}$, mammalian target of rapamycin.

*Publication addresses multiple organ systems; ${ }^{\dagger}$ Publication also contains pre-clinical data. 


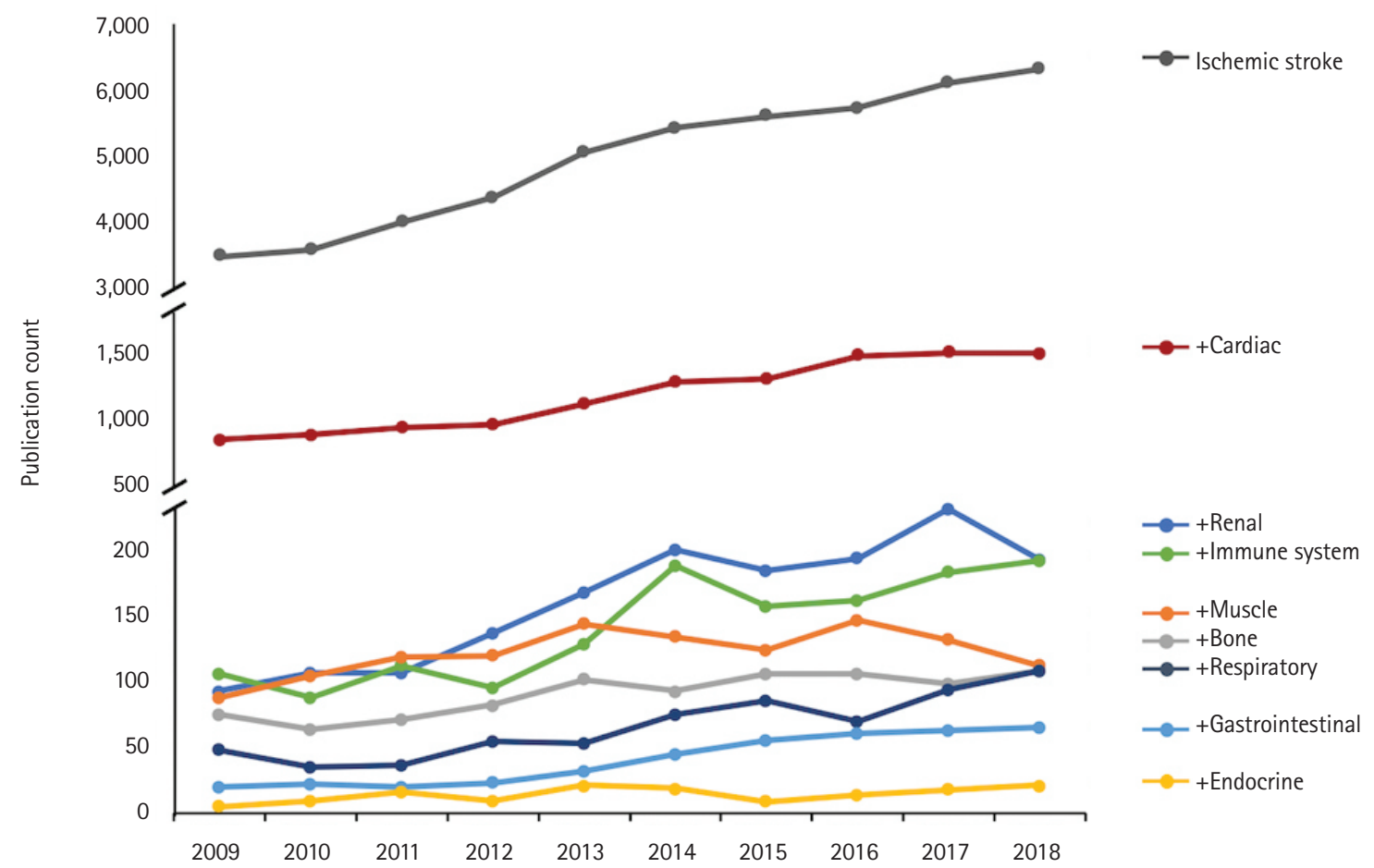

Supplementary Figure 1. A decade of ischemic stroke literature. Ischemic stroke drives development of systemic pathologies. Queries of stroke literature by year (National Center for Biotechnology Information and National Library of Medicine database; PubMed) show annual ischemic stroke publications have steadily increased in number since 2009. However, searches of ischemic stroke literature associated with various system-specific terminology (e.g., [(ischemic stroke) AND cardiac]) revealed little attention has been given to peripheral consequences of stroke over the past decade. Indeed, in 2018 when ischemic stroke publications numbered more than 6,000, seven of the eight peripheral systems examined had less than 200 publications, five of which had 100 or less. The eighth system reflected cardiac outcomes in ischemic stroke at around 1,400 publications-more in comparison given the clinical link in cardio- and cerebrovascular research-though still a mere fraction overall. Data are reported as publication count (y-axis; split twice to denote full spread across systems) by publication year ( $\mathrm{x}$-axis). 


\section{Supplementary references}

1. Offner $H$, Subramanian $S$, Parker SM, Afentoulis ME, Vandenbark AA, Hurn PD. Experimental stroke induces massive, rapid activation of the peripheral immune system. $J$ Cereb Blood Flow Metab 2006;26:654-665.

2. Offner $H$, Subramanian $S$, Parker $S M$, Wang $C$, Afentoulis $M E$, Lewis $A$, et al. Splenic atrophy in experimental stroke is accompanied by increased regulatory T cells and circulating macrophages. J Immuno/ 2006;176:6523-6531.

3. Gu L, Xiong X, Zhang H, Xu B, Steinberg GK, Zhao H. Distinctive effects of $T$ cell subsets in neuronal injury induced by cocultured splenocytes in vitro and by in vivo stroke in mice. Stroke 2012;43:1941-1946.

4. Gu L, Xiong X, Wei D, Gao X, Krams S, Zhao H. T cells contribute to stroke-induced lymphopenia in rats. PLoS One 2013;8:e59602.

5. Braun JS, Prass K, Dirnagl U, Meisel A, Meisel C. Protection from brain damage and bacterial infection in murine stroke by the novel caspase-inhibitor Q-VD-OPH. Exp Neurol 2007;206:183-191.

6. Wong $\mathrm{CH}$, Jenne $\mathrm{CN}$, Lee $\mathrm{WY}$, Léger $\mathrm{C}$, Kubes P. Functional innervation of hepatic iNKT cells is immunosuppressive following stroke. Science 2011;334:101-105.

7. Kim ID, Lee H, Kim SW, Lee HK, Choi J, Han PL, et al. Alarmin HMGB1 induces systemic and brain inflammatory exacerbation in post-stroke infection rat model. Cell Death Dis 2018;9:426.

8. Walker PA, Shah SK, Jimenez F, Gerber MH, Xue H, Cutrone $\mathrm{R}$, et al. Intravenous multipotent adult progenitor cell therapy for traumatic brain injury: preserving the blood brain barrier via an interaction with splenocytes. Exp Neurol 2010;225:341-352.

9. Ajmo CT Jr, Vernon DO, Collier L, Hall AA, Garbuzova-Davis $S$, Willing $A$, et al. The spleen contributes to stroke-induced neurodegeneration. J Neurosci Res 2008;86:22272234.

10. Dotson AL, Wang J, Saugstad J, Murphy SJ, Offner H. Splenectomy reduces infarct volume and neuroinflammation in male but not female mice in experimental stroke. $J$ Neuroimmunol 2015;278:289-298.

11. Kim E, Yang J, Beltran CD, Cho S. Role of spleen-derived monocytes/macrophages in acute ischemic brain injury. $J$ Cereb Blood Flow Metab 2014;34:1411-1419.

12. Zierath D, Shen A, Stults A, Olmstead T, Becker KJ. Splenectomy does not improve long-term outcome after stroke. Stroke 2017;48:497-500.

13. Belinga VF, Wu GJ, Yan FL, Limbenga EA. Splenectomy following MCAO inhibits the TLR4-NF-KB signaling pathway and protects the brain from neurodegeneration in rats. J Neuroimmunol 2016;293:105-113.

14. Kharrazian D. Traumatic brain injury and the effect on the brain-gut axis. Altern Ther Health Med 2015;21 Suppl 3:28-32.

15. Kigerl KA, Mostacada K, Popovich PG. Gut microbiota are disease-modifying factors after traumatic spinal cord injury. Neurotherapeutics 2018;15:60-67.

16. Singh V, Roth S, Llovera G, Sadler R, Garzetti D, Stecher B, et al. Microbiota dysbiosis controls the neuroinflammatory response after stroke. J Neurosci 2016;36:7428-7440.

17. Stanley D, Moore RJ, Wong CHY. An insight into intestinal mucosal microbiota disruption after stroke. Sci Rep 2018; 8:568.

18. Winek $K$, Engel 0 , Koduah $P_{\text {, Heimesaat } M M}$, Fischer $A_{\text {, }}$ Bereswill $\mathrm{S}$, et al. Depletion of cultivatable gut microbiota by broad-spectrum antibiotic pretreatment worsens outcome after murine stroke. Stroke 2016;47:1354-1363.

19. Tascilar N, Irkorucu O, Tascilar O, Comert F, Eroglu O, Bahadir $\mathrm{B}$, et al. Bacterial translocation in experimental stroke: what happens to the gut barrier? Bratisl Lek Listy 2010;111:194-199.

20. Benakis C, Brea D, Caballero S, Faraco G, Moore J, Murphy $M$, et al. Commensal microbiota affects ischemic stroke outcome by regulating intestinal $\gamma \delta$ T cells. Nat Med 2016;22:516-523.

21. Crapser J, Ritzel R, Verma R, Venna VR, Liu F, Chauhan A, et al. Ischemic stroke induces gut permeability and enhances bacterial translocation leading to sepsis in aged mice. Aging (Albany NY) 2016;8:1049-1063.

22. Oyama N, Winek K, Bäcker-Koduah P, Zhang T, Dames C, Werich $\mathrm{M}$, et al. Exploratory investigation of intestinal function and bacterial translocation after focal cerebral ischemia in the mouse. Front Neurol 2018;9:937.

23. Chamorro Á, Meisel A, Planas AM, Urra $X$, van de Beek $D$, Veltkamp R. The immunology of acute stroke. Nat Rev Neurol 2012;8:401-410.

24. Liu Q, Jin WN, Liu Y, Shi K, Sun H, Zhang F, et al. Brain ischemia suppresses immunity in the periphery and brain via different neurogenic innervations. Immunity 2017;46: 474-487.

25. Johnston KC, Li JY, Lyden PD, Hanson SK, Feasby TE, Adams RJ, et al. Medical and neurological complications of ischemic stroke: experience from the RANTTAS trial. RANTTAS Investigators. Stroke 1998;29:447-453.

26. Chiu NL, Kaiser B, Nguyen YV, Welbourne S, Lall C, Cramer $\mathrm{SC}$. The volume of the spleen and its correlates after acute 
stroke. J Stroke Cerebrovasc Dis 2016;25:2958-2961.

27. Vogelgesang A, Grunwald U, Langner $S$, Jack R, Bröker

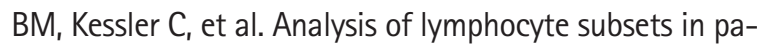
tients with stroke and their influence on infection after stroke. Stroke 2008;39:237-241.

28. Mocco J, Wilson DA, Komotar RJ, Sughrue ME, Coates K, Sacco RL, et al. Alterations in plasma complement levels following human ischemic stroke. Neurosurgery 2006;59:1-6.

29. Planas AM, Gómez-Choco M, Urra X, Gorina $R$, Caballero $M$, Chamorro Á. Brain-derived antigens in lymphoid tissue of patients with acute stroke. J Immunol 2012;188:21562163.

30. Yang $\mathrm{QW}$, Lu FL, Zhou Y, Wang L, Zhong $\mathrm{Q}$, Lin S, et al. HMBG1 mediates ischemia-reperfusion injury by TRIFadaptor independent toll-like receptor 4 signaling. J Cereb Blood Flow Metab 2011;31:593-605.

31. Liesz A, Dalpke A, Mracsko E, Antoine DJ, Roth S, Zhou W, et al. DAMP signaling is a key $p$ athway inducing immune modulation after brain injury. J Neurosci 2015;35:583-598.

32. Harms H, Prass K, Meisel C, Klehmet J, Rogge W, Drenck-

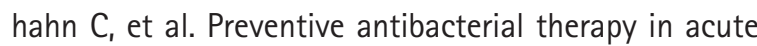
ischemic stroke: a randomized controlled trial. PLoS One 2008;3:e2158.

33. Hug A, Dalpke A, Wieczorek N, Giese T, Lorenz A, Auffarth $G$, et al. Infarct volume is a major determiner of poststroke immune cell function and susceptibility to infection. Stroke 2009;40:3226-3232.

34. Hernández-Jiménez $E$, Gutierrez-Fernández $M$, CubillosZapata C, Otero-Ortega L, Rodríguez-Frutos B, Toledano $V$, et al. Circulating monocytes exhibit an endotoxin tolerance status after acute ischemic stroke: mitochondrial DNA as a putative explanation for poststroke infections. $J$ Immunol 2017;198:2038-2046.

35. Hoffmann S, Harms $H$, Ulm L, Nabavi DG, Mackert BM, Schmehl I, et al. Stroke-induced immunodepression and dysphagia independently predict stroke-associated pneumonia: the PREDICT study. J Cereb Blood Flow Metab 2017;37:3671-3682.

36. van de Beek D, Wijdicks EF, Vermeij FH, de Haan RJ, Prins $J M$, Spanjaard L, et al. Preventive antibiotics for infections in acute stroke: a systematic review and meta-analysis. Arch Neurol 2009;66:1076-1081.

37. Badve MS, Zhou Z, Anderson CS, Hackett ML. Effectiveness and safety of antibiotics for preventing pneumonia and improving outcome after acute stroke: systematic review and meta-analysis. J Stroke Cerebrovasc Dis 2018;27:31373147.

38. Yin J, Liao SX, He Y, Wang S, Xia GH, Liu FT, et al. Dysbio- sis of gut microbiota with reduced trimethylamine-n-oxide level in patients with large-artery atherosclerotic stroke or transient ischemic attack. J Am Heart Assoc 2015:4:e002699.

39. Stanley D, Mason $\sqcup$, Mackin KE, Srikhanta YN, Lyras D, Prakash MD, et al. Translocation and dissemination of commensal bacteria in post-stroke infection. Nat Med 2016:22:1277-1284.

40. Yamashiro K, Tanaka R, Urabe T, Ueno Y, Yamashiro Y, Nomoto $K$, et al. Gut dysbiosis is associated with metabolism and systemic inflammation in patients with ischemic stroke. PLoS One 2017;12:e0171521.

41. Yamashiro $K$, Tanaka R, Urabe T, Ueno Y, Yamashiro Y, Nomoto $\mathrm{K}$, et al. Correction: gut dysbiosis is associated with metabolism and systemic inflammation in patients with ischemic stroke. PLoS One 2017;12:e0176062.

42. Prass K, Meisel C, Höflich C, Braun J, Halle E, Wolf T, et al. Stroke-induced immunodeficiency promotes spontaneous bacterial infections and is mediated by sympathetic activation reversal by poststroke $T$ helper cell type 1-like immunostimulation. J Exp Med 2003;198:725-736.

43. Ajmo CT Jr, Collier LA, Leonardo CC, Hall AA, Green SM, Womble TA, et al. Blockade of adrenoreceptors inhibits the splenic response to stroke. Exp Neurol 2009;218:4755.

44. Yan FL, Zhang JH. Role of the sympathetic nervous system and spleen in experimental stroke-induced immunodepression. Med Sci Monit 2014;20:2489-2496.

45. Mracsko E, Liesz A, Karcher S, Zorn M, Bari F, Veltkamp R. Differential effects of sympathetic nervous system and hypothalamic-pituitary-adrenal axis on systemic immune cells after severe experimental stroke. Brain Behav Immun 2014:41:200-209.

46. Ay I, Sorensen $A G, A y H$. Vagus nerve stimulation reduces infarct size in rat focal cerebral ischemia: an unlikely role for cerebral blood flow. Brain Res 2011;1392:110-115.

47. Han Z, Shen F, He Y, Degos V, Camus M, Maze M, et al. Activation of a-7 nicotinic acetylcholine receptor reduces ischemic stroke injury through reduction of pro-inflammatory macrophages and oxidative stress. PLoS One 2014; 9:e105711.

48. Engel 0 , Akyüz $L$, da Costa Goncalves AC, Winek K, Dames $C$, Thielke $M$, et al. Cholinergic pathway suppresses pulmonary innate immunity facilitating pneumonia after stroke. Stroke 2015;46:3232-3240.

49. Chamorro A, Amaro S, Vargas M, Obach V, Cervera A, Gómez-Choco $M$, et al. Catecholamines, infection, and death in acute ischemic stroke. J Neurol Sci 2007;252:29-35. 
50. McCulloch L, Smith CJ, McColl BW. Adrenergic-mediated loss of splenic marginal zone $B$ cells contributes to infection susceptibility after stroke. Nat Commun 2017;8:15051.

51. Dziedzic T, Slowik A, Pera J, Szczudlik A. Beta-blockers reduce the risk of early death in ischemic stroke. J Neurol Sci 2007;252:53-56.

52. Sykora M, Siarnik P, Diedler J; VISTA Acute Collaborators. $\beta$-Blockers, pneumonia, and outcome after ischemic stroke: evidence from virtual international stroke trials archive. Stroke 2015;46:1269-1274.

53. De Raedt S, Haentjens P, De Smedt A, Brouns R, Uyttenboogaart M, Luijckx GJ, et al. Pre-stroke use of betablockers does not affect ischaemic stroke severity and outcome. Eur J Neurol 2012;19:234-240.

54. Maier IL, Becker JC, Leyhe JR, Schnieder M, Behme D, Psychogios MN, et al. Influence of beta-blocker therapy on the risk of infections and death in patients at high risk for stroke induced immunodepression. PLoS One 2018;13:e0196174.

55. Westendorp WF, Vermeij JD, Brouwer MC, Roos YB, Nederkoorn PJ, van de Beek D, et al. Pre-stroke use of beta-blockers does not lower post-stroke infection rate: an exploratory analysis of the preventive antibiotics in stroke study. Cerebrovasc Dis 2016;42:506-511.

56. Starr JB, Tirschwell DL, Becker KJ. Increased infections with $\beta$-blocker use in ischemic stroke, a $\beta 2$-receptor mediated process? Neurol Sci 2017;38:967-974.

57. Harms $H_{1}$ Reimnitz $P$, Bohner $G$, Werich $T$, Klingebiel $R_{a}$

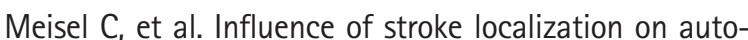
nomic activation, immunodepression, and post-stroke infection. Cerebrovasc Dis 2011;32:552-560.

58. Haeusler KG, Schmidt WU, Föhring F, Meisel $C_{1}$ Helms T, Jungehulsing $\mathrm{GJ}$, et al. Cellular immunodepression preceding infectious complications after acute ischemic stroke in humans. Cerebrovasc Dis 2008;25:50-58.

59. Barugh AJ, Gray P, Shenkin SD, MacLullich AM, Mead GE. Cortisol levels and the severity and outcomes of acute stroke: a systematic review. J Neurol 2014;261:533-545.

60. Prass K, Braun JS, Dirnagl U, Meisel C, Meisel A. Stroke propagates bacterial aspiration to pneumonia in a model of cerebral ischemia. Stroke 2006;37:2607-2612.

61. Suda S, Aoki J, Shimoyama T, Suzuki K, Sakamoto Y, Katano $T$, et al. Stroke-associated infection independently predicts 3-month poor functional outcome and mortality. J Neurol 2018;265:370-375.

62. Walter U, Knoblich R, Steinhagen V, Donat M, Benecke R, Kloth $A$. Predictors of pneumonia in acute stroke patients admitted to a neurological intensive care unit. J Neurol 2007;254:1323-1329.
63. Lakshminarayan $\mathrm{K}$, Tsai AW, Tong $\mathrm{X}$, Vazquez G, Peacock $J M$, George MG, et al. Utility of dysphagia screening results in predicting poststroke pneumonia. Stroke 2010;41:28492854.

64. Kalra L, Irshad S, Hodsoll J, Simpson M, Gulliford M, Smithard $D$, et al. Prophylactic antibiotics after acute stroke for reducing pneumonia in patients with dysphagia (STROKE-INF): a prospective, cluster-randomised, openlabel, masked endpoint, controlled clinical trial. Lancet 2015;386:1835-1844.

65. Xi YG, Tian X, Chen WQ, Zhang S, Zhang S, Ren WD, et al. Antibiotic prophylaxis for infections in patients with acute stroke: a systematic review and meta-analysis of randomized controlled trials. Oncotarget 2017;8:8107581087.

66. Kelly J, Rudd A, Lewis RR, Coshall C, Moody A, Hunt BJ. Venous thromboembolism after acute ischemic stroke: a prospective study using magnetic resonance direct thrombus imaging. Stroke 2004;35:2320-2325.

67. Pilato $F$, Calandrelli R, Profice P, Della Marca G, Broccolini $A$, Bello $G$, et al. Pulmonary embolism in a stroke patient after systemic thrombolysis: clinical decisions and literature review. JStroke Cerebrovasc Dis 2013;22:e667-e670.

68. Pongmoragot J, Rabinstein $A A$, Nilanont $Y$, Swartz $R H$, Zhou L, Saposnik G, et al. Pulmonary embolism in ischemic stroke: clinical presentation, risk factors, and outcome. J Am Heart Assoc 2013;2:e000372.

69. Bembenek JP, Karlinski M, Kobayashi A, Czlonkowska A. Deep venous thrombosis in acute stroke patients. Clin Appl Thromb Hemost 2012;18:258-264.

70. Douds GL, Hellkamp AS, Olson DM, Fonarow GC, Smith EE, Schwamm LH, et al. Venous thromboembolism in the Get With The Guidelines-Stroke acute ischemic stroke population: incidence and patterns of prophylaxis. J Stroke Cerebrovasc Dis 2014;23:123-129.

71. Rinde LB, Småbrekke B, Mathiesen EB, Løchen ML, Njølstad I, Hald EM, et al. Ischemic stroke and risk of venous thromboembolism in the general population: the Tromsø study. J Am Heart Assoc 2016;5:e004311.

72. Sandercock PA, Counsell C, Kane EJ. Anticoagulants for acute ischaemic stroke. Cochrane Database Syst Rev 2015; 2015:CD000024.

73. CLOTS (Clots in Legs Or sTockings after Stroke) Trials Collaboration, Dennis M, Sandercock P, Reid J, Graham C, Forbes $J$, et al. Effectiveness of intermittent pneumatic compression in reduction of risk of deep vein thrombosis in patients who have had a stroke (CLOTS 3): a multicentre randomised controlled trial. Lancet 2013;382:516- 
524.

74. Dennis M, Sandercock P, Graham C, Forbes J; CLOTS (Clots in Legs Or sTockings after Stroke) Trials Collaboration, Smith J. The Clots in Legs Or sTockings after Stroke (CLOTS) 3 trial: a randomised controlled trial to determine whether or not intermittent pneumatic compression reduces the risk of post-stroke deep vein thrombosis and to estimate its cost-effectiveness. Health Technol Assess 2015;19:1-90.

75. Morelli VM, Sejrup JK, Småbrekke B, Rinde LB, Grimnes $G$, Isaksen $T$, et al. The role of stroke as a trigger for incident venous thromboembolism: results from a population-based case-crossover study. TH Open 2019;3:e50-e57.

76. Ersoz M, Ulusoy H, Oktar MA, Akyuz M. Urinary tract infection and bacteriurua in stroke patients: frequencies, pathogen microorganisms, and risk factors. Am J Phys Med Rehabil 2007;86:734-741.

77. Indredavik B, Rohweder G, Naalsund E, Lydersen S. Medical complications in a comprehensive stroke unit and an early supported discharge service. Stroke 2008;39:414420.

78. Stott DJ, Falconer A, Miller H, Tilston JC, Langhorne P. Urinary tract infection after stroke. OJM 2009;102:243-249.

79. Ifejika-Jones NL, Peng $H$, Noser EA, Francisco GE, Grotta JC. Hospital-acquired symptomatic urinary tract infection in patients admitted to an academic stroke center affects discharge disposition. PM R 2013;5:9-15.

80. Huang WC, Wann SR, Lin SL, Kunin CM, Kung MH, Lin $\mathrm{CH}_{\text {, }}$ et al. Catheter-associated urinary tract infections in intensive care units can be reduced by prompting physicians to remove unnecessary catheters. Infect Control Hosp Epidemiol 2004;25:974-978.

81. Topal J, Conklin S, Camp K, Morris V, Balcezak T, Herbert P. Prevention of nosocomial catheter-associated urinary tract infections through computerized feedback to physicians and a nurse-directed protocol. Am J Med Qual 2005;20:121-126.

82. Titsworth WL, Hester J, Correia T, Reed R, Williams M, Guin $\mathrm{P}$, et al. Reduction of catheter-associated urinary tract infections among patients in a neurological intensive care unit: a single institution's success. J Neurosurg 2012;116:911-920.

83. Chen SC, Chen PY, Chen GC, Chuang SY, Tzeng IS, Lin SK. Portable bladder ultrasound reduces incidence of urinary tract infection and shortens hospital length of stay in patients with acute ischemic stroke. J Cardiovasc Nurs 2018;33:551-558.

84. Muramatsu K, Fujino Y, Kubo T, Otani M, Fushimi K, Mat- suda S. Efficacy of antimicrobial catheters for prevention of catheter-associated urinary tract infection in acute cerebral infarction. J Epidemiol 2018;28:54-58.

85. Hachinski VC, Oppenheimer SM, Wilson JX, Guiraudon C, Cechetto DF. Asymmetry of sympathetic consequences of experimental stroke. Arch Neurol 1992;49:697-702.

86. Dziedzic T, Slowik A, Szczudlik A. Urine albumin excretion in acute ischaemic stroke is related to serum interleukin-6. Clin Chem Lab Med 2004;42:182-185.

87. Thomas LH, Coupe J, Cross LD, Tan AL, Watkins CL. Interventions for treating urinary incontinence after stroke in adults. Cochrane Database Syst Rev 2019;2:CD004462.

88. Pettersen R, Wyller TB. Prognostic significance of micturition disturbances after acute stroke. J Am Geriatr Soc 2006;54:1878-1884.

89. Lee SJ, Lee DG. Relationship between kidney dysfunction and ischemic stroke outcomes: albuminuria, but not estimated glomerular filtration rate, is associated with the risk of further vascular events and mortality after stroke. PLoS One 2016;11:e0155939.

90. Tsagalis G, Akrivos T, Alevizaki M, Manios E, Stamatellopoulos $K$, Laggouranis $A$, et al. Renal dysfunction in acute stroke: an independent predictor of long-term all combined vascular events and overall mortality. Nephrol Dial Transplant 2009;24:194-200.

91. Shrestha P, Thapa S, Shrestha S, Lohani S, Bk S, MacCormac 0 , et al. Renal impairment in stroke patients: a comparison between the haemorrhagic and ischemic variants. Version 2. F1000Res 2017;6:1531.

92. Khatri $\mathrm{M}$, Himmelfarb J, Adams D, Becker K, Longstreth WT, Tirschwell DL. Acute kidney injury is associated with increased hospital mortality after stroke. J Stroke Cerebrovasc Dis 2014;23:25-30.

93. Nadkarni GN, Patel AA, Konstantinidis I, Mahajan A, Agarwal SK, Kamat $S$, et al. Dialysis requiring acute kidney injury in acute cerebrovascular accident hospitalizations. Stroke 2015;46:3226-3231.

94. Zorrilla-Vaca A, Ziai W, Connolly ES Jr, Geocadin R, Thompson R, Rivera-Lara L. Acute kidney injury following acute ischemic stroke and intracerebral hemorrhage: a meta-analysis of prevalence rate and mortality risk. Cerebrovasc Dis 2018:45:1-9.

95. Arnold J, Ng KP, Sims D, Gill P, Cockwell P, Ferro C. Incidence and impact on outcomes of acute kidney injury after a stroke: a systematic review and meta-analysis. $B M C$ Nephrol 2018;19:283.

96. Wu CL, Tsai CC, Kor CT, Tarng DC, Lian leB, Yang TH, et al. Stroke and risks of development and progression of kidney 
diseases and end-stage renal disease: a nationwide population-based cohort study. PLoS One 2016;11:e0158533.

97. Jia S, Xia Q, Zhang B, Wang L. Involvement of the paraventricular nucleus in the occurrence of arrhythmias in middle cerebral artery occlusion rats. J Stroke Cerebrovasc Dis 2015;24:844-851.

98. Bieber M, Werner RA, Tanai E, Hofmann U, Higuchi T, Schuh $\mathrm{K}$, et al. Stroke-induced chronic systolic dysfunction driven by sympathetic overactivity. Ann Neurol 2017;82:729-743.

99. Daniele O, Caravaglios G, Fierro B, Natalè E. Stroke and cardiac arrhythmias. J Stroke Cerebrovasc Dis 2002;11:2833.

100. Di Pasquale G, Pinelli G, Grazi P, Andreoli A, Corbelli C, Manini $G L$, et al. Incidence of silent myocardial ischaemia in patients with cerebral ischaemia. Eur Heart J 1988;9 Suppl N:104-107.

101. Adams RJ, Chimowitz MI, Alpert JS, Awad IA, Cerqueria $M D$, Fayad $P$, et al. Coronary risk evaluation in patients with transient ischemic attack and ischemic stroke: a scientific statement for healthcare professionals from the Stroke Council and the Council on Clinical Cardiology of the American Heart Association/American Stroke Association. Stroke 2003;34:2310-2322.

102. Ay H, Koroshetz WJ, Benner T, Vangel MG, Melinosky C, Arsava EM, et al. Neuroanatomic correlates of stroke-related myocardial injury. Neurology 2006;66:1325-1329.

103. Touzé E, Varenne O, Chatellier G, Peyrard S, Rothwell PM, Mas JL. Risk of myocardial infarction and vascular death after transient ischemic attack and ischemic stroke: a systematic review and meta-analysis. Stroke 2005;36:27482755.

104. Joundi RA, Rabinstein AA, Nikneshan D, Tu JV, Fang J, Holloway $R$, et al. Cardiac arrest in acute ischemic stroke: incidence, predisposing factors, and clinical outcomes. $J$ Stroke Cerebrovasc Dis 2016;25:1644-1652.

105. Prosser J, MacGregor L, Lees KR, Diener HC, Hacke W, Davis $\mathrm{S}$, et al. Predictors of early cardiac morbidity and mortality after ischemic stroke. Stroke 2007;38:2295-2302.

106. Yoshimura S, Toyoda $K_{1}$ Ohara T, Nagasawa $H_{\text {, Ohtani }} \mathrm{N}_{\text {, }}$ Kuwashiro T, et al. Takotsubo cardiomyopathy in acute ischemic stroke. Ann Neurol 2008;64:547-554.

107. Jung JM, Kim JG, Kim JB, Cho KH, Yu S, Oh K, et al. Takotsubo-like myocardial dysfunction in ischemic stroke: a hospital-based registry and systematic literature review. Stroke 2016;47:2729-2736.

108. Milionis $H$, Faouzi $M$, Cordier $M, D^{\prime}$ Ambrogio-Remillard $S$, Eskandari A, Michel P. Characteristics and early and longterm outcome in patients with acute ischemic stroke and low ejection fraction. Int J Cardiol 2013;168:1082-1087.

109. Colivicchi F, Bassi A, Santini M, Caltagirone C. Cardiac autonomic derangement and arrhythmias in right-sided stroke with insular involvement. Stroke 2004;35:20942098.

110. Laowattana S, Zeger SL, Lima JA, Goodman SN, Wittstein IS, Oppenheimer SM. Left insular stroke is associated with adverse cardiac outcome. Neurology 2006;66:477-483.

111. Korpelainen JT, Huikuri HV, Sotaniemi KA, Myllylä W. Abnormal heart rate variability reflecting autonomic dysfunction in brainstem infarction. Acta Neurol Scand 1996; 94:337-342.

112. Francica JV, Bigongiari A, Mochizuki L, Scapini KB, Moraes OA, Mostarda $C$, et al. Cardiac autonomic dysfunction in chronic stroke women is attenuated after submaximal exercise test, as evaluated by linear and nonlinear analysis. BMC Cardiovasc Disord 2015;15:105.

113. Tahsili-Fahadan P, Geocadin RG. Heart-brain axis: effects of neurologic injury on cardiovascular function. Circ Res 2017; 120:559-572.

114. Xu $X, Z$ Zhu $Y$, Chuai J. Changes in serum ghrelin and small intestinal motility in rats with ischemic stroke. Anat Rec (Hoboken) 2012;295:307-312.

115. Feng $W$, Vasquez $G$, Suri MF, Lakshminarayan $K$, Qureshi Al. Repeated-measures analysis of the National Institute of Neurological Disorders and Stroke rt-PA stroke trial. $J$ Stroke Cerebrovasc Dis 2011;20:241-246.

116. Hsu $\mathrm{HL}$, Lin $Y H$, Huang $Y C$, Weng $H H$, Lee $M$, Huang WY, et al. Gastrointestinal hemorrhage after acute ischemic stroke and its risk factors in Asians. Eur Neurol 2009;62:212-218.

117. Chen $\mathrm{CM}$, Hsu HC, Chuang YW, Chang $\mathrm{CH}$, Lin $\mathrm{CH}$, Hong CZ. Study on factors affecting the occurrence of upper gastrointestinal bleeding in elderly acute stroke patients undergoing rehabilitation. J Nutr Health Aging 2011;15:632636.

118. Ogata T, Kamouchi M, Matsuo R, Hata J, Kuroda J, Ago T, et al. Gastrointestinal bleeding in acute ischemic stroke: recent trends from the fukuoka stroke registry. Cerebrovasc Dis Extra 2014;4:156-164.

119. Li J, Yuan M, Liu Y, Zhao Y, Wang J, Guo W. Incidence of constipation in stroke patients: a systematic review and meta-analysis. Medicine (Baltimore) 2017;96:e7225.

120. Harari D, Coshall C, Rudd AG, Wolfe CD. New-onset fecal incontinence after stroke: prevalence, natural history, risk factors, and impact. Stroke 2003;34:144-150.

121. Schaller BJ, Graf R, Jacobs AH. Pathophysiological changes of the gastrointestinal tract in ischemic stroke. $A m$ J Gastroenterol 2006;101:1655-1665. 
122. Yi JH, Chun MH, Kim BR, Han EY, Park JY. Bowel function in acute stroke patients. Ann Rehabil Med 2011;35:337343.

123. Ottani A, Giuliani D, Mioni C, Galantucci M, Minutoli L, Bitto $A$, et al. Vagus nerve mediates the protective effects of melanocortins against cerebral and systemic damage after ischemic stroke. J Cereb Blood Flow Metab 2009;29:512523.

124. Puchowicz MA, Zechel JL, Valerio J, Emancipator DS, Xu K, Pundik $S$, et al. Neuroprotection in diet-induced ketotic rat brain after focal ischemia. J Cereb Blood Flow Metab 2008;28:1907-1916.

125. Koch K, Berressem D, Konietzka J, Thinnes A, Eckert GP, Klein J. Hepatic ketogenesis induced by middle cerebral artery occlusion in mice. J Am Heart Assoc 2017;6:e005556.

126. Wang $Y Y$, Lin SY, Chuang $Y H$, Sheu WH, Tung KC, Chen CJ. Activation of hepatic inflammatory pathways by catecholamines is associated with hepatic insulin resistance in male ischemic stroke rats. Endocrinology 2014;155:1235-1246.

127. Pineda S, Bang OY, Saver JL, Starkman S, Yun SW, Liebeskind DS, et al. Association of serum bilirubin with ischemic stroke outcomes. J Stroke Cerebrovasc Dis 2008;17:147152.

128. Luo Y, Li J, Zhang J, Xu Y. Elevated bilirubin after acute ischemic stroke linked to the stroke severity. Int J Dev Neurosci 2013;31:634-638.

129. Muscari A, Collini A, Fabbri E, Giovagnoli M, Napoli C,

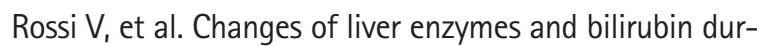
ing ischemic stroke: mechanisms and possible significance. BMC Neurol 2014;14:122.

130. Zhu CZ, Auer RN. Optimal blood glucose levels while using insulin to minimize the size of infarction in focal cerebral ischemia. J Neurosurg 2004;101:664-668.

131. Szczudlik A, Slowik A, Turaj W, Wyrwicz-Petkow U, Pera J, Dziedzic $T$, et al. Transient hyperglycemia in ischemic stroke patients. J Neurol Sci 2001;189:105-111.

132. Baird TA, Parsons MW, Phan T, Butcher KS, Desmond PM, Tress BM, et al. Persistent poststroke hyperglycemia is independently associated with infarct expansion and worse clinical outcome. Stroke 2003;34:2208-2214.

133. Vancheri F, Curcio M, Burgio A, Salvaggio $S$, Gruttadauria $\mathrm{G}$, Lunetta $\mathrm{MC}$, et al. Impaired glucose metabolism in patients with acute stroke and no previous diagnosis of diabetes mellitus. OJM 2005;98:871-878.

134. Ntaios G, Egli M, Faouzi M, Michel P. J-shaped association between serum glucose and functional outcome in acute ischemic stroke. Stroke 2010;41:2366-2370.

135. Gray CS, Hildreth AJ, Alberti GK, O'Connell JE; GIST Col- laboration. Poststroke hyperglycemia: natural history and immediate management. Stroke 2004;35:122-126.

136. Bruno A, Kent TA, Coull BM, Shankar RR, Saha C, Becker $\mathrm{KJ}$, et al. Treatment of hyperglycemia in ischemic stroke (THIS): a randomized pilot trial. Stroke 2008;39:384-389.

137. Bruno A, Durkalski VL, Hall CE, Juneja R, Barsan WG, Janis $S$, et al. The Stroke Hyperglycemia Insulin Network Effort (SHINE) trial protocol: a randomized, blinded, efficacy trial of standard vs. intensive hyperglycemia management in acute stroke. Int J Stroke 2014;9:246-251.

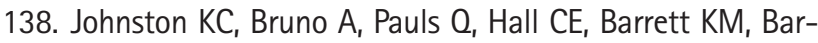

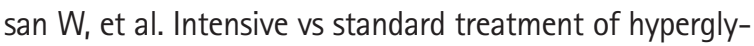
cemia and functional outcome in patients with acute ischemic stroke: the SHINE randomized clinical trial. JAMA 2019;322:326-335.

139. Sadana P, Coughlin L, Burke J, Woods R, Mdzinarishvili A. Anti-edema action of thyroid hormone in MCAO model of ischemic brain stroke: possible association with AQP4 modulation. J Neurol Sci 2015;354:37-45.

140. Zhang Y, Meyer MA. Clinical analysis on alteration of thyroid hormones in the serum of patients with acute ischemic stroke. Stroke Res Treat 2010;2010:290678.

141. Cho HJ, Kim SS, Sung SM, Jung DS. Impact of thyroid autoantibodies on functional outcome in patients with acute ischemic stroke. J Stroke Cerebrovasc Dis 2014;23:19151920.

142. Meng H, Liu T, Borjigin J, Wang MM. Ischemic stroke destabilizes circadian rhythms. J Circadian Rhythms 2008;6:9.

143. Bhattacharya P, Pandey AK, Paul S, Patnaik R. Melatonin renders neuroprotection by protein kinase $\mathrm{C}$ mediated aquaporin-4 inhibition in animal model of focal cerebral ischemia. Life Sci 2014;100:97-109.

144. Kilic E, Kilic U, Yulug B, Hermann DM, Reiter RJ. Melatonin reduces disseminate neuronal death after mild focal ischemia in mice via inhibition of caspase- 3 and is suitable as an add-on treatment to tissue-plasminogen activator. J Pineal Res 2004;36:171-176.

145. Kilic U, Kilic E, Reiter RJ, Bassetti CL, Hermann DM. Signal transduction pathways involved in melatonin-induced neuroprotection after focal cerebral ischemia in mice. $J$ Pineal Res 2005;38:67-71.

146. Manev H, Uz T, Kharlamov A, Joo JY. Increased brain damage after stroke or excitotoxic seizures in melatonin-deficient rats. FASEB J 1996;10:1546-1551.

147. Ritzenthaler T, Nighoghossian N, Berthiller J, Schott AM, Cho TH, Derex $L$, et al. Nocturnal urine melatonin and 6-sulphatoxymelatonin excretion at the acute stage of ischaemic stroke. J Pineal Res 2009;46:349-352. 
148. Vinogradov OI, Ivanova DS, Davidov NP, Kuznetsov AN. Melatonin in the correction of sleep in post-stroke patients. Zh Nevrol Psikhiatr Im S S Korsakova 2015;115:8689.

149. Borschmann KN, Rewell SS, Iuliano S, Ghasem-Zadeh $A$, Davey RA, Ho $\mathrm{H}$, et al. Reduced bone formation markers, and altered trabecular and cortical bone mineral densities of non-paretic femurs observed in rats with ischemic stroke: a randomized controlled pilot study. PLoS One 2017; 12:e0172889.

150. Vignaux G, Ndong JD, Perrien DS, Elefteriou F. Inner ear vestibular signals regulate bone remodeling via the sympathetic nervous system. J Bone Miner Res 2015;30:11031111.

151. Kanis J, Oden $A_{1}$ Johnell 0 . Acute and long-term increase in fracture risk after hospitalization for stroke. Stroke 2001;32:702-706.

152. Pang MY, Eng JJ. Muscle strength is a determinant of bone mineral content in the hemiparetic upper extremity: implications for stroke rehabilitation. Bone 2005;37:103111.

153. Pang MY, Ashe MC, Eng JJ. Muscle weakness, spasticity and disuse contribute to demineralization and geometric changes in the radius following chronic stroke. Osteoporos Int 2007;18:1243-1252.

154. Kapral MK, Fang J, Alibhai SM, Cram P, Cheung AM, Casaubon LK, et al. Risk of fractures after stroke: results from the Ontario Stroke Registry. Neurology 2017;88:5764.

155. Borschmann K, Iuliano S, Ghasem-Zadeh A, Churilov L, Pang MYC, Bernhardt J. Upright activity and higher motor function may preserve bone mineral density within 6 months of stroke: a longitudinal study. Arch Osteoporos 2018;13:5.

156. Desgeorges MM, Devillard X, Toutain J, Divoux D, Castells J, Bernaudin $\mathrm{M}$, et al. Molecular mechanisms of skeletal muscle atrophy in a mouse model of cerebral ischemia. Stroke 2015;46:1673-1680.

157. Springer J, Schust S, Peske K, Tschirner A, Rex A, Engel O, et al. Catabolic signaling and muscle wasting after acute ischemic stroke in mice: indication for a stroke-specific sarcopenia. Stroke 2014;45:3675-3683.

158. Sen CK, Khanna S, Harris H, Stewart R, Balch M, Heigel M, et al. Robot-assisted mechanical therapy attenuates stroke-induced limb skeletal muscle injury. FASEB J 2017;31:927-936.

159. Desgeorges MM, Devillard X, Toutain J, Castells J, Divoux $D$, Arnould DF, et al. Pharmacological inhibition of myo- statin improves skeletal muscle mass and function in a mouse model of stroke. Sci Rep 2017;7:14000.

160. Jørgensen $L$, Jacobsen BK. Changes in muscle mass, fat mass, and bone mineral content in the legs after stroke: a 1 year prospective study. Bone 2001;28:655-659.

161. Benecke R, Berthold A, Conrad B. Denervation activity in the EMG of patients with upper motor neuron lesions: time course, local distribution and pathogenetic aspects. J Neurol 1983;230:143-151.

162. De Deyne PG, Hafer-Macko CE, Ivey FM, Ryan AS, Macko RF. Muscle molecular phenotype after stroke is associated with gait speed. Muscle Nerve 2004;30:209-215.

163. Ryan AS, Ivey FM, Prior S, Li G, Hafer-Macko C. Skeletal muscle hypertrophy and muscle myostatin reduction after resistive training in stroke survivors. Stroke 2011;42:416420.

164. Scherbakov N, von Haehling S, Anker SD, Dirnagl U, Doehner W. Stroke induced Sarcopenia: muscle wasting and disability after stroke. Int J Cardiol 2013;170:89-94.

165. Benjamin EJ, Muntner P, Alonso A, Bittencourt MS, Callaway $C W$, Carson AP, et al. Heart disease and stroke statistics: 2019 update. A report from the American Heart Association. Circulation 2019;139:e56-e528.

166. GBD 2016 Neurology Collaborators. Global, regional, and national burden of neurological disorders, 1990-2016: a systematic analysis for the Global Burden of Disease Study 2016. Lancet Neurol 2019;18:459-480.

167. GBD 2016 Stroke Collaborators. Global, regional, and national burden of stroke, 1990-2016: a systematic analysis for the Global Burden of Disease Study 2016. Lancet Neurol 2019;18:439-458.

168. 168. Powers WJ, Rabinstein AA, Ackerson $T$, Adeoye OM, Bambakidis NC, Becker K, et al. 2018 Guidelines for the early management of patients with acute ischemic stroke: a guideline for healthcare professionals from the American Heart Association/American Stroke Association. Stroke 2018;49:e46-e110.

169. Pierot L, Jayaraman MV, Szikora I, Hirsch JA, Baxter B, Miyachi $S$, et al. Standards of practice in acute ischemic stroke intervention: international recommendations. $J$ Neurointerv Surg 2018;10:1121-1126.

170. Sacks D, Baxter B, Campbell BCV, Carpenter JS, Cognard C, Dippel D, et al. Multisociety consensus quality improvement revised consensus statement for endovascular therapy of acute ischemic stroke: from the American Association of Neurological Surgeons (AANS), American Society of Neuroradiology (ASNR), Cardiovascular and Interventional Radiology Society of Europe (CIRSE), Canadian In- 
terventional Radiology Association (CIRA), Congress of Neurological Surgeons (CNS), European Society of Minimally Invasive Neurological Therapy (ESMINT), European Society of Neuroradiology (ESNR), European Stroke Organization (ESO), Society for Cardiovascular Angiography and Interventions (SCAI), Society of Interventional Radiology (SIR), Society of Neurolnterventional Surgery (SNIS), and World Stroke Organization (WSO). J Vasc Interv Radiol 2018;29:441-453.

171. Johnson W, Onuma O, Owolabi M, Sachdev S. Stroke: a global response is needed. Bull World Health Organ 2016;94:634-634A.

172. Winstein CJ, Stein J, Arena R, Bates B, Cherney LR, Cramer $\mathrm{SC}$, et al. Guidelines for adult stroke rehabilitation and recovery: a guideline for healthcare professionals from the American Heart Association/American Stroke Association. Stroke 2016;47:e98-e169.

173. Platz T. Evidence-based guidelines and clinical pathways in stroke rehabilitation-an international perspective. Front Neurol 2019;10:200. 